Elsevier required licence: (C) $<2020>$. This manuscript version is made available under the CC-BY-NCND 4.0 license http://creativecommons.org/licenses/by-nc-nd/4.0/

The definitive publisher version is available online at

[https://www.sciencedirect.com/science/article/abs/pii/S0959652619332445?via\%3Dihub] 


\section{Redesigning a food supply chain for environmental sustainability - An analysis of resource use and recovery}

\section{Introduction}

Considering the world population is expected to reach 9.6 billion by 2050, and with it the demand for food (up by $70 \%$ of its current level). A significant problem remains - that 'one-third of global food production is wasted or lost annually'(FAO, 2011a, p. 11). When food products are wasted, the resources used in their production and distribution along the food supply chain (FSC) (such as fuel, water, fertilisers, pesticides and raw materials) are also wasted (Göbel et al., 2015). This high level of resource consumption and unnecessary food wastage causes significant adverse impacts on profits, natural resources, ecosystems and human health (Gokarn and Kuthambalayan, 2017). These FSCs are also responsible for $31 \%$ of greenhouse gas emissions and for more than $50 \%$ of eutrophication (Tukker and Jansen, 2006). The total carbon footprint corresponding to the food

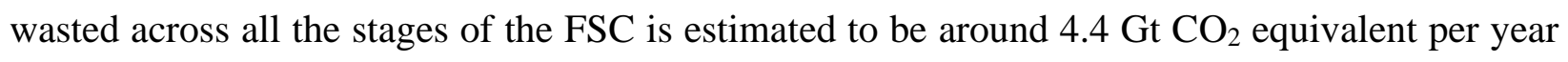
(FAO, 2011b). This degree of environmental impact is more prevalent in developing countries

such as India, due to their ineffective practices across cultivation, processing, packing and the transportation stages of the FSC (FAO, 2011a). So, the adoption of sustainable environmental practices is becoming a necessity rather than a preference (Bligny et al., 2012; Govindan, 2018).

With a focus on environmental sustainability, it is essential to assess the environmental impact of resources consumed across all the stages of the FSC and to identify mitigation opportunities. Several studies have applied Circular Economy (CE) principles to improve resource-use efficiency by extending the lifetime use of a resource through a process of resource recovery (through reuse/recycle - a process of eliminating waste). CE principles primarily focus on a closed loop process that uses waste as an input within the supply chains (MacArthur, 2013a), thus increasing the amount of waste reused/recycled (Banasik et al., 2017a, 2017b). CE is "expected to promote economic growth by creating new businesses and job opportunities, saving materials' cost, dampening price volatility, improving security of supply while at the same time reducing environmental pressures and social impacts" (Kalmykova et al., 2018, p. 190), thereby addressing all three dimensions of sustainability (Seuring and Müller, 2008), simultaneously.

On the other hand, several studies have also focused on improving operational efficiencies. These include inventory management (Akbari Kaasgari et al., 2017), lean production (Garza-Reyes et al., 
2018), network optimisation (Banasik et al., 2017a) as well as scheduling and sequencing of operations (Agustina et al., 2014). Ultimately, applying resource recovery practices reduces food wastage and extends the lifetime use of virgin material. Consequently, such operational efficiency improvement practices improve the operational efficiency of the processes and thereby optimize the amount of resources consumed and waste generated.

Whilst India is the major producer and exporter of many agricultural crops (FAO, 2014), there is a lack of research that evaluates the environmental impact of the Indian FSCs (Soto-Silva et al., 2016). The environmental impact of the same product varies according to the resources consumed (Beitzen-Heineke et al., 2017) and so it is important that the environmental impact of individual supply chains be considered. Furthermore, there are only a few studies that identify operational and resource inefficiency, as well as the opportunity to reduce it by way of Life Cycle Assessment (LCA) (Noya et al., 2017). Likewise, existing literature fails to provide a framework accounting for best practices that improves operational efficiency and resource recovery to attain environmental sustainability.

Based on these gaps in the literature, this study aims to assess the environmental impact of an Indian FSC using the Life Cycle Assessment (LCA) approach that has been widely adopted in literature as a method of conducting an environmental impact assessment (Garofalo et al., 2017; Noya et al., 2018a). Figure 1 presents the theoretical framework used in this paper to address the above research gaps identified from literature. The LCA approach calculates the environmental impact of resources consumed across cultivation, processing, packaging and transportation stages of the mango FSC in India. The Indian mango has been chosen as the case product in this study given that India is the largest exporter of mango product (APEDA, 2018) and the amount of food waste (FW) associated with it is quite significant (Arora et al., 2018). The results of the LCA assists decision makers to identify operational and resource inefficiencies present in the FSC (Manfredi and Vignali, 2014). 


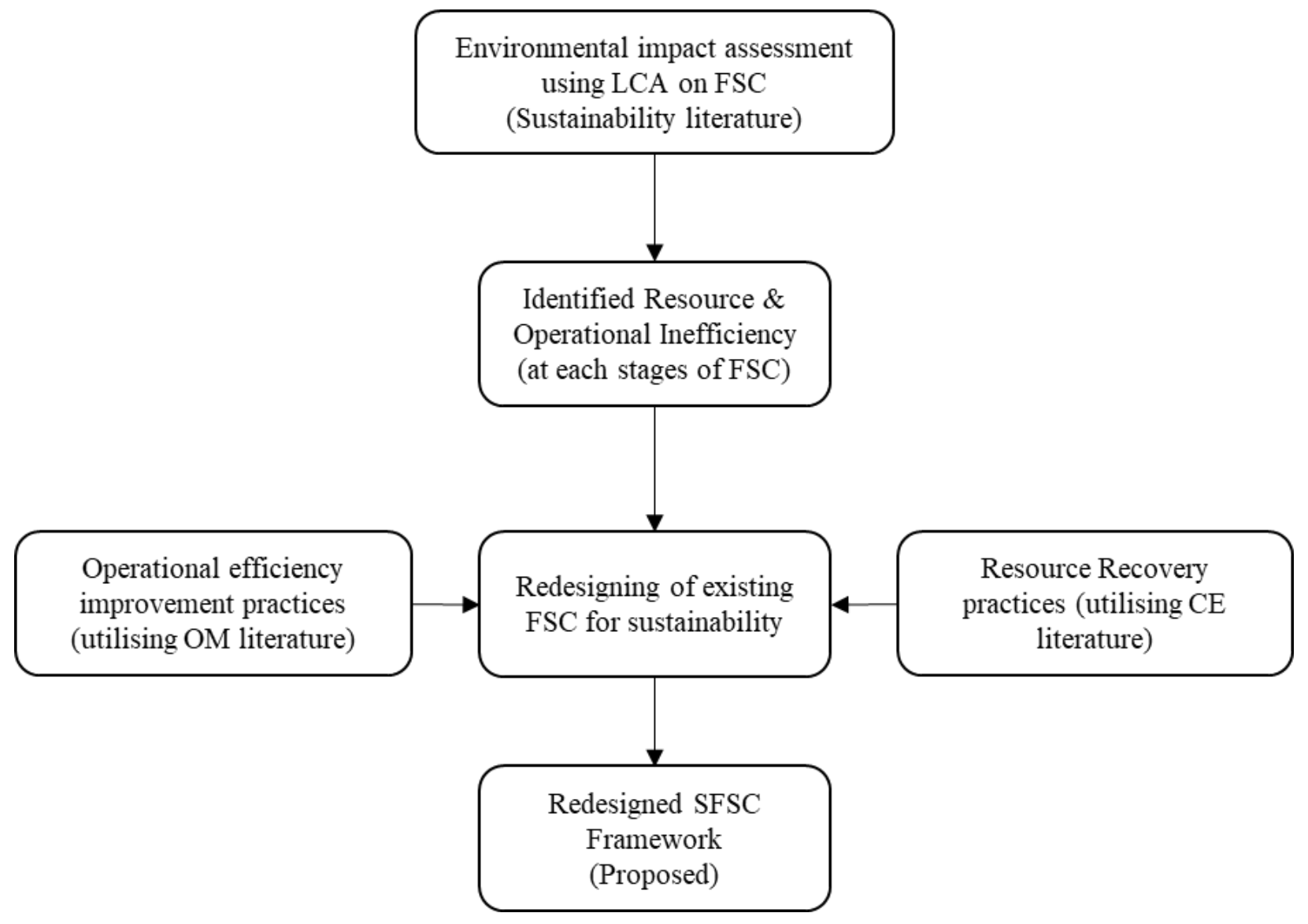

Figure 1 A theoretical sustainable food supply chain framework

To address these inefficiencies, a Sustainable Food Supply Chain (SFSC) framework is proposed by redesigning the FSC through the adoption of practices that improves operational efficiency and resource efficiency, with our prime focus on improving environmental sustainability, including identification of economic and social benefits where possible. An economic model for SFSC is also developed to show how the redesigned FSC will reduce the consumption of virgin materials and increase agricultural production with no additional use of resources.

The rest of this paper is organised as follows. In Section 2, a literature review of the various topics pertinent to this research is presented. This is followed by Section 3 which discusses the development of the SFSC conceptual framework and Section 4 that measures the extent of the resources used and identifies inefficiencies using an LCA approach. Section 5 draws upon the LCA results to recommend a redesigned mango FSC for environmental sustainability. Finally. Section 6 concludes by considering the managerial implications of these findings for the FSC 
broadly, particularly in the context of a growing world population that will become dependent on more efficient food production processes.

\section{Literature review}

This section provides a brief literature review on SFSC, operational efficiency improvement practices, CE practices and use of LCA tools in FSC relevant to this study. The review emphasises the need for the adoption of environmental sustainability practices in the context of FSC.

\subsection{Sustainable food supply chain}

The food industry is the largest manufacturing sector in many developed and developing countries (Egilmez et al., 2014). With the ever-increasing demand for food products propelled by an increasing population, a large amount of natural resources is consumed. This not only impacts the crop yield but also results in ineffective practices and unsustainable ways of consuming the natural resources. Although there are known efficient food production and distribution systems, SFSC remains a challenge worldwide (Irani and Sharif, 2016). For example, more than 175 million people in India and 130 million in China are consuming food products grown by excessive use of water. Meanwhile, more than $24 \%$ of families are facing foodless days in India (Brown, 2012).

Whilst being cognizant of the economic benefits, there are growing environmental, social and ethical concerns as a result of the growing demand on natural resources for agricultural production. As such consumers, policy-makers and organisations are pressuring markets in particular for better management of environmental resources across all stages of the FSC (Iakovou et al., 2015). In addition, consumers have started demanding information about quality, safety, sustainability, the origin of the products, resources consumed and shelf life of the product, which have a direct impact on FSC decisions (Beske et al., 2014). Adding to these pressures are the concerns associated with climate change, localism and fair trade (D. Li et al., 2014). These challenges are focus squarely on how food can be cultivated, distributed and consumed in a sustainable way.

The environmental dimension of sustainability mainly focuses on issues related to environmental management. Such issues include depletion of natural resources (Yusuf et al., 2013), release of toxic gases into the environment (Paksoy et al., 2011), energy consumption (Cholette and Venkat, 2009), water consumption (Labuschagne et al., 2005) and waste generation (Tsai and Hung, 2009). Environmental impact assessment of resources consumed across the stages of the FSC assists in 
identifying inefficiencies and mitigation strategies. The literature on environmental impact assessment of FSC is discussed next.

\subsection{Environmental impact assessment - Life cycle assessment applied in FSC}

Quantification of environmental impact provides a detailed analysis of where all the resources are spent and its corresponding environmental impact. This measure supports decision makers by providing alternative strategies. Several methodologies have been developed for this purpose including LCA (Longo et al., 2017), material flow analysis (Ju et al., 2017; Yin et al., 2015) and emergy analysis (Liu et al., 2019; Park et al., 2016). LCA is the most commonly used method in literature for assessing environmental impacts of different agricultural production systems (Roy et al., 2009) and for the selection of environmentally friendly practices and equipment (Notarnicola et al., 2017). For this reason, the LCA method is adopted in this study to analyse the environmental impact of an FSC.

The LCA tool models the environmental impact of complex FSCs as it takes into account all the resources used and emissions released across all stages of the FSC. Manfredi and Vignali (2014) performed a LCA study on tomato puree production and identified packaging as having the greatest environmental impact, as a significant amount of energy was required during the production of the glass packaging material. Borghi et al. (2014) similarly concluded from an LCA study on tomato-based products that packaging of the processed food resulted in the highest environmental impact. Garofalo et al. (2017) found that the waste produced during the processing phase generated the greatest environmental impact, followed by the packaging and the cropping phase of the canned tomato cultivation. These studies illustrate that an assessment of a similar product' (tomato in this case) can result in different environmental impacts due to the variations in the type and quantity of resources consumed. Similar work has also been done for agricultural food processing activities (see Kyriakopoulou et al., 2015), dairy products and (see Noya et al., 2018b; Parajuli et al., 2018).

A study by Willersinn et al. (2015) has concluded that environmental benefits are more in case of loss treatments performed to obtain value from FW as against loss reduction scenarios. Therefore, implementation of waste recovery practices in FSCs are likely to have significant positive impacts on the environment. 
Noya et al. (2017) used the LCA approach to evaluate the environmental performance of the linear pork chain in Catalonia. Based on the result of an LCA, they found that both fodder production and transport activities are the critical stages of the system. To address these critical stages, based on CE principles, authors have proposed alternate options including the economic valorisation of its main co-products (blood and butter) along with the optimisation of fodder production using both local ingredients and pig slurry (from the farm) as an organic fertiliser. This alternate option resulted in a reduction in environmental impact by $13.4 \%$ in transportation activities and $2 \%$ in co-products and waste. Hence, resource recovery practices will result in reduced environmental impact.

\subsection{Resource recovery practices applied in FSC}

Though the idea of CE has been in public discourse for some time, it gained momentum more recently with the work produced by the Ellen Macarthur Foundation (MacArthur, 2013b; Su et al., 2013). The Foundation defines $\mathrm{CE}$ as a generic term for an industrial economy that is, by design or intention, restorative and in which material flows are of two types: (i) biological nutrients intended to re-enter the biosphere safely, and (ii) technical nutrients, intended to circulate at a high quality without entering the biosphere. The waste generated in a linear economy (extract, make, use and dispose) is not present in the values underpinning the CE philosophy (extract, make, use, re-use). Instead, waste is considered as a resource input into other products or into other supply chains. Overall, the goal of CE is to retain as much valuable materials through a resource-efficient processes of production (Hobson, 2016) which may at times depend on new business model innovations (Sharpe and Agarwal, 2014). As an example, the seawater-based agricultural model implemented in Eritrea has an ecosystem designed to utilise the output of one species as an input for another, while maximising the value generated in terms of the economic, environmental and social outcomes (see Jeffries (2017).

$\mathrm{CE}$ in underpinned by three principles that address the challenges faced by linear economies. The first principle (P1) emphasises preserving and enhancing natural capital, like soil nutrients and water resources through controlling and balancing the scarce resources. The second principle (P2) addresses optimisation of resources through remanufacturing, refurbishing and recycling products within their technical and biological cycles. In the case of FSC, principle P2 is achieved by the use of by-products from food processing and recovering nutrients from waste in innovative ways that 
create value (Mirabella et al., 2014) in the same or new supply chain. The third principle (P3) focuses on generating incremental value through ecosystem effectiveness by managing externalities such as water, climate change and the release of toxic substances into the environment.

In developing countries, around $20-30 \%$ of food waste takes place in the pre-harvest stages of FSCs due to "limitations in harvesting techniques, storage and cooling facilities, infrastructure, packaging and marketing systems" (Bharucha, 2018, p. 640), that result in significant environmental impacts (Brancoli et al., 2017). Despite India being the second largest producer of fruits in the world, around $72 \%$ of fruits harvested are wasted along the FSC due to poor facility and infrastructure for storage, cold chain and processing facilities (Balaji and Arshinder, 2016). Given the extent of current levels of food waste, it is imperative to identify possible solutions to help mitigate this volume of waste. For example, peels and seeds of fruits contain bioactive compounds such as polyphenols, carotenoids and dietary fibres that could supplement vitamins (Ajila et al., 2010). Other valuable compounds can also be obtained from food waste, including pectin, dietary fibre, phenolic and other antioxidants. Anbazhagan, (2016) found that fruit and vegetable wastes, tea dust, cattle waste and poultry scraps can be converted into enriched plant nutrients by adding algal. Similarly, in FSCs, waste from every stage of the supply chain could be recovered through appropriate resource recovery practices.

\subsection{Operational efficiency improvement practices applied in FSC}

FSCs involves a series of activities spanning from cultivation to distribution that brings food products from farms to the end customers (Aramyan et al., 2006). Perishability, long lead-time for producing agricultural products, seasonality in production and consumption and unsustainable consumption of natural resources warrants the efficient management of resources (Amorim et al., 2013; Siddh et al., 2017).

Various optimisation models have been developed for ensuring optimal usage of resources across the different stages of the FSC. The models have been notably created for inventory management, network design, waste elimination, quality improvement and scheduling, etc. For example, Ahumada and Villalobos (2011) have developed an operational model that supports the short-term planning (operational) decisions in the fresh produce industry for harvesting, packing and distribution of crops to maximise revenue. 
Optimisation of resources consumed such as water, fertilizer and energy are the main concerns in the cultivation stage. Development of a sensor-based technology for precision agriculture is one example of optimisation. Such technology has been developed to supply only the required amount of inputs to the crops when required, reducing the resources consumed while simultaneously increasing the yield obtained (Bongiovanni and Lowenberg-Deboer, 2004).

Next in the processing stage, consideration includes the selection of suppliers (Govindan et al., 2017), location of facilities (Pishvaee and Razmi, 2012), production planning (Banasik et al., 2017b), inventory decisions (Mogale et al., 2017) and selection of technology (Eskandarpour et al., 2015). As expected, the success of any business depends on the management of relationships with customer and suppliers (Parwez, 2014). There are multiple criteria that influence the selection of the best suppliers. Criteria include supply capacity, quantity flexibility, quality of supply, price of the product, sustainability initiatives, location of the supplier and timely delivery (Azadnia et al., 2015; Grimm et al., 2016). As a result of pressures from customers on sustainability, industries have started to consider environmental and social criteria in addition to cost when selecting the supplier (Banaeian et al., 2018). Multi-criteria decision-making approaches such as analytic hierarchy process are widely used by supply chain managers to assist in supplier selection decisions (Grimm et al., 2014). Kumar et al. (2014) used a data envelopment analysis based approach to address the supplier selection problem considering carbon footprint and cost factors. Prosman and Sacchi, (2016) have developed environmental supplier selection criteria for the circular supply chain. Considering supplier profitability, technological capability, conformance quality, relationship closeness and conflict resolution factors, Dulmin and Mininno (2003) proposed a solution to a supplier selection problem based on a fuzzy systematic approach.

Moreover, network design is one of the key influencing factors for sustainability in FSCs (Allaoui et al., 2018). Network design involves the decision concerning the best configuration and operation of all the supply chain network elements such as processing facilities, logistics, warehouses and extraction facilities, to maximise the economic and social benefits and minimise the environmental impacts (Allaoui et al., 2018; Pishvaee and Razmi, 2012). Much of the research in this area primarily focuses on economic considerations (Ahumada and Villalobos, 2011). Only a few studies have considered more than one sustainable dimension in network optimisation models. For example, Mota et al. (2015) developed a decision support model for the integrated design and 
planning of sustainable supply chains using optimisation modelling taking into account uncertainty. Banasik et al. (2017a) developed mixed integer linear programming models taking into account environmental and economic considerations.

Babazadeh et al. (2017) considered minimising total cost and environmental impact in the biodiesel supply chain network, using a multi-objective-possibilistic programming model. Results showed that high investment cost is required for minimising the environmental impact and risk. Rentizelas et al., (2018) optimised the end-to-end supply chain of agricultural plastic waste recycling. Zhang and Jiang, (2017) developed a model to find the optimal design of the supply chain which is focusing on extraction of biodiesel from waste cooking oil. Papapostolou et al., (2011) developed an optimisation model for the optimal design of the biofuel supply chain considering both technical and economic parameters that affect the performance. Akgul et al., (2012) developed a multi-objective optimisation model considering economic and environmental factors to find the optimal design of hybrid first/second generation bio-fuel supply chain. Sharifzadeh et al., (2015) developed an optimisation model for biofuel supply chain design and operation under uncertain conditions. Validi et al. (2014) presented a robust solution approach for the design of a capacitated distribution network for a two-layer supply chain involved in the distribution of milk in Ireland. Allaoui et al., (2018) developed a multi-objective linear supply chain model that aims to select effective suppliers from a proposed set of suppliers and to locate a given number of effective transformers and distributors to satisfy the demands of the clients.

Lean manufacturing tools such as total productive maintenance, value stream mapping, Kaizen, 5S (Sort, Set In order, Shine, Standardise and Sustain) and root cause analysis are widely applied in processing industries to eliminate the non-value-added activities and reduce the resource consumption (Piercy and Rich, 2015; So and Sun, 2015). Garza-Reyes et al. (2018) investigated the impact of lean tools on environmental performance in terms of material use, waste production and energy consumption. Value stream mapping is a lean tool that identifies and measures nonvalue-added activities resulting from inefficiencies and unreliability of money, people, machines, information, tools and material during the course of a production process (Rother and Shook, 2003). Through correlation analysis and structural equation modelling, authors have concluded that total productive maintenance and just in time production have positive influences on environmental performance (Garza-Reyes et al., 2018). 
In the packaging and distribution stages, studies have considered the inventory decisions (Soysal et al., 2015), packaging material selection (Galotto and Ulloa, 2010) and transportation decisions (Mogale et al., 2017). Li et al. (2014) developed a model to address the dynamic lot sizing considering product returns and remanufacturing, which determines the production schedule of manufacturing new products or remanufactured products to meet the demand at the lowest cost. Accorsi et al., (2014) proposed a conceptual framework to integrate the design of food packaging and distribution networks. This also included an environmental and economic impact assessment of replacing the existing single-use packaging material with reusable plastic containers. However, reusable packaging material also comes with additional environmental costs associated with transportation (Mogale et al., 2016). As such, it can be said that the choice of material should also depend on the supply location.

It is evident from the literature that the environmental impact from the production even of similar products can vary depending on the amount of resource consumed in the process (Beitzen-Heineke et al., 2017). Therefore, it is important to assess the environmental impact of individual supply chains corresponding to the resources consumed across the various stages of the FSC. What is missing in the literature is how the results from such environmental assessments can be used to address these problems (Noya et al., 2017). What is also evident from the current literature is the absence (or gap) of relevant frameworks that suggest how the existing FSC may be redesigned to a SFSC to address the operational and resource inefficiencies that have been suitably measured for sustainable outcomes.

\section{Conceptual Framework}

With this gap in mind, a SFSC conceptual framework for the redesigning of an existing FSC is proposed and illustrated in Figure 2. In order to address the FSC operational and resource inefficiencies across all stages and make the FSC more sustainable, a number of operational efficiency improvement practices and CE-based resource recovery practices are proposed to design a SFSC.

Key operational efficiency improvement practices contribute to reductions in resource use and waste produced are shown on the left side of Figure 2. Similarly, resource recovery practices that provide opportunities for reducing/reusing/recycling of waste and other by-products that increase the lifecycle use of inputs into production, are shown on the right side of Figure 2. Overall, 
improving operational efficiency can reduce the amount of resource consumed and waste generated in an FSC and thus reduce the effort required for resource recovery. This interaction is illustrated using dotted arrows.

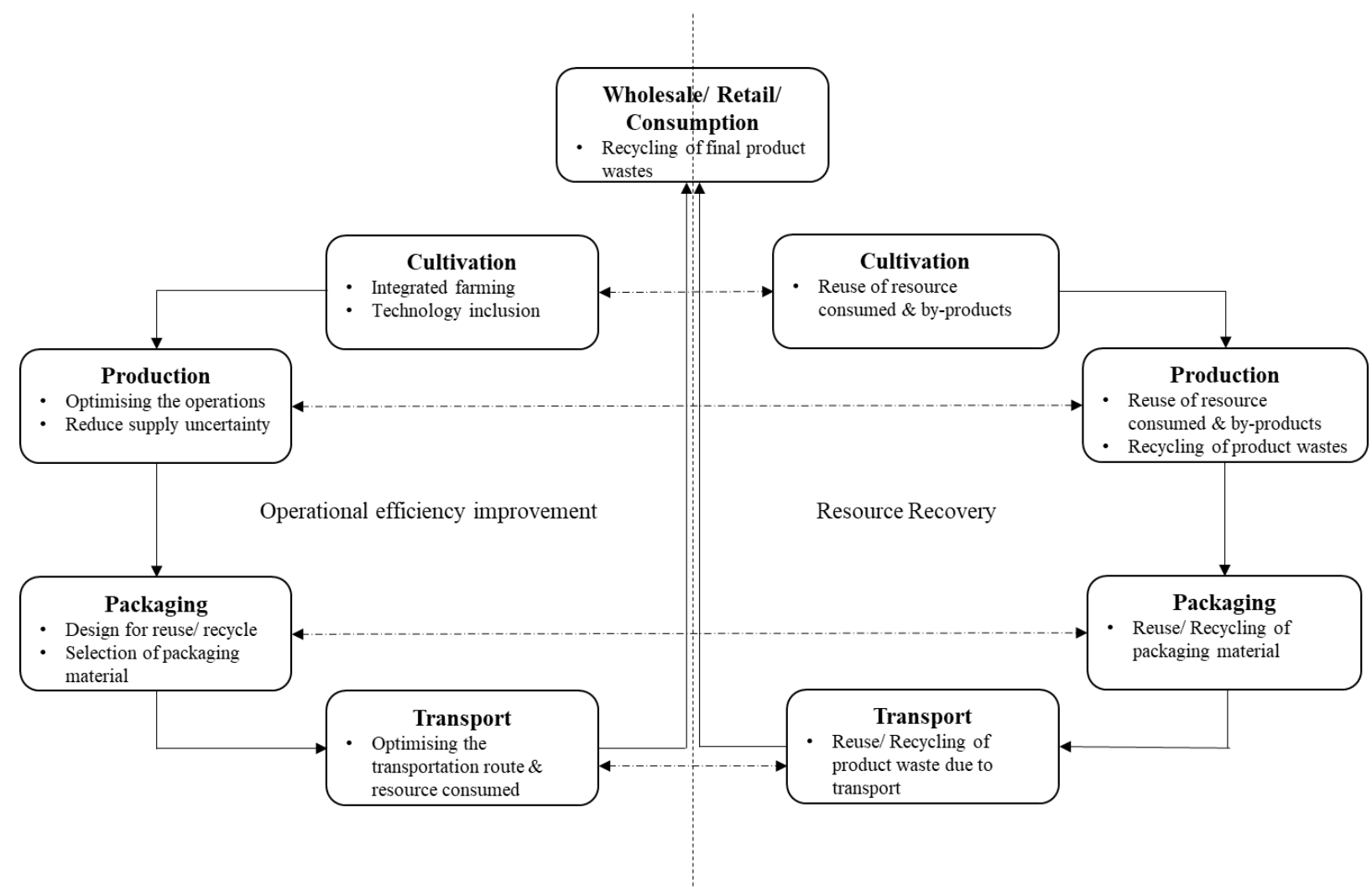

Figure 2 SFSC conceptual framework for improving operational efficiency and resource recovery

A redesigned FSC that improves both operational efficiency and resource recovery results in value creation. This can be explained using an economic framework. Figure 3, illustrates the effects of input-resource substitution (virgin to recycled materials) in the farming sector considering the growing CE industries that support recycling. Further, Figure 4 shows the reduction in inputresource use (both virgin and recycled materials) that results from improving operational efficiencies in the cultivation stage of an FSC. Both these effects combine to reduce the volume of virgin input-resources required within the cultivation stage of the FSC. This result thereby contributes to a more closed loop production system (Winkler, 2011). In both cases, labour and capital stock are assumed to be given and the focus is solely on input resource use. This is to illustrate that current agricultural practices in the cultivation stage are not only foregoing the opportunity to use recycled products back into production but are failing to address the 
inefficiencies in production that may result in additional CE activity through recycling. In effect, they are more likely to happen at the expense of unnecessary use of virgin material that is needed to support inefficiencies in production.

Specifically, in Figure 3, all the farmers' total expenditure on input-resource used in agricultural production is represented as the downward slope isocost line $C_{1} C_{1}^{A}$. The inputs in agricultural production include virgin material, recycled material, or a combination of the two. Labour and capital inputs are assumed as given. The line $C_{1} C_{1}^{A}$ represents a level of current expenditure on input-resources, where $C_{1}$ represents the maximum amount of virgin material consumed if current the expenditure is entirely on these inputs. $C_{1}^{A}$ represents the maximum amount of recycled material consumed if current the expenditure is entirely based on recycled materials. It is unlikely that commercial farming can be entirely dependent on recycled material and so some amount of virgin material is assumed. A point on the line $C_{1} C_{1}^{A}$ represents a quantity combination of the two inputs that can be purchased at current expenditure levels.

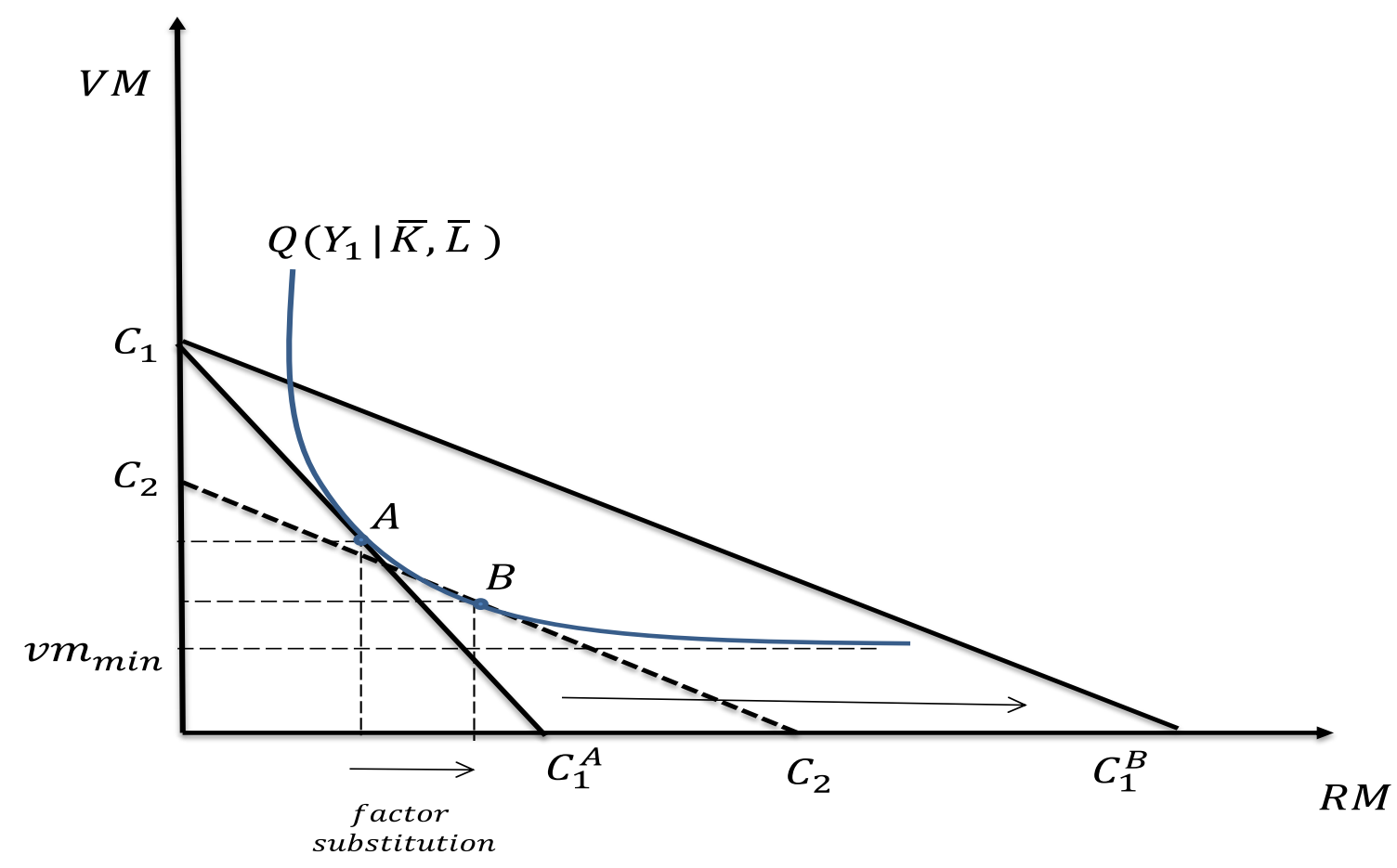

Figure 3 Resource Substitution Effect from CE Practices (RM - Recycled Material, VM - Virgin Material)

The combination of inputs is chosen based on the target level of production that is driven by a number of factors. In particular, this involves the ease by which the raw materials can be sourced, 
their quality (especially for recycled materials) as well as their price and the techniques/technology used in production. In this example, it is assumed there is a given level and quality of capital in the production of a given level of output. In Figure 3, the level of agricultural production chosen by farmers is point A (equal to $Y_{1}$ output) where the isoquant $Q\left(Y_{1} \mid \bar{K}, \bar{L}\right)$ is tangential to the isocostcurve $C_{1} C_{1}^{A}$. The quantity of capital $(\mathrm{K})$ and labour $(\mathrm{L})$ are fixed in the current period.

The use of waste arising from harvesting, transporting and processing creates an opportunity to reintroduce recycled inputs back into the FSC or other organisation. Our focus in this example is on the recycled use of waste in the FSC. The greater the volume of waste that becomes recycled through an expanding CE industry, the higher the accessibility of recycled inputs. Subsequently, the price for the recycled material is reduced. The effect of a fall in price is shown in Figure 3 as a rotation of the isocost line $C_{1} C_{1}^{A}$ to $C_{1} C_{1}^{B}$. By shifting back the isocost line $C_{1} C_{1}^{B}$ to $Q\left(Y_{1} \mid \bar{K}, \bar{L}\right)$, the new tangency points on the isocost line $C_{2} C_{2}$ show the substitution of virgin material by use of recycled material. At lower relative prices for recycled materials, farmers are encouraged to switch from virgin material use to recycled materials in agricultural production (assuming quality consistency of recycled material). Figure 3 shows the level of input-resource substitution as resources move from point $\mathrm{A}$ to $\mathrm{B}$. As expected, the growth in the $\mathrm{CE}$ industries results in a greater uptake of recycled inputs into production.

Figure 4 depicts the effects of input-resource use from improvements made in operational efficiency. In contrast to the assumption made in Figure 3, it is assumed that both production and technical inefficiency exist at point B. Efforts to reduce or eliminate this inefficiency will result in a reduction of input-resource use for the same level of production $\mathrm{Y}_{1}$. The effects of improvements in operational efficiency are illustrated in Figure 4 as a leftward shift of the isocost line to $C_{3} C_{3}$. The new isoquant $Q^{*}\left(Y_{1} \mid \bar{K}, \bar{L}\right)$ that represents the same level of output $\mathrm{Y}_{1}$ is now tangent to $C_{3} C_{3}$ at point $\mathrm{C}$. Use of both virgin material and recycled material has declined as a result of this, however, use of the recycled material continues largely as was the case in Figure 3. 


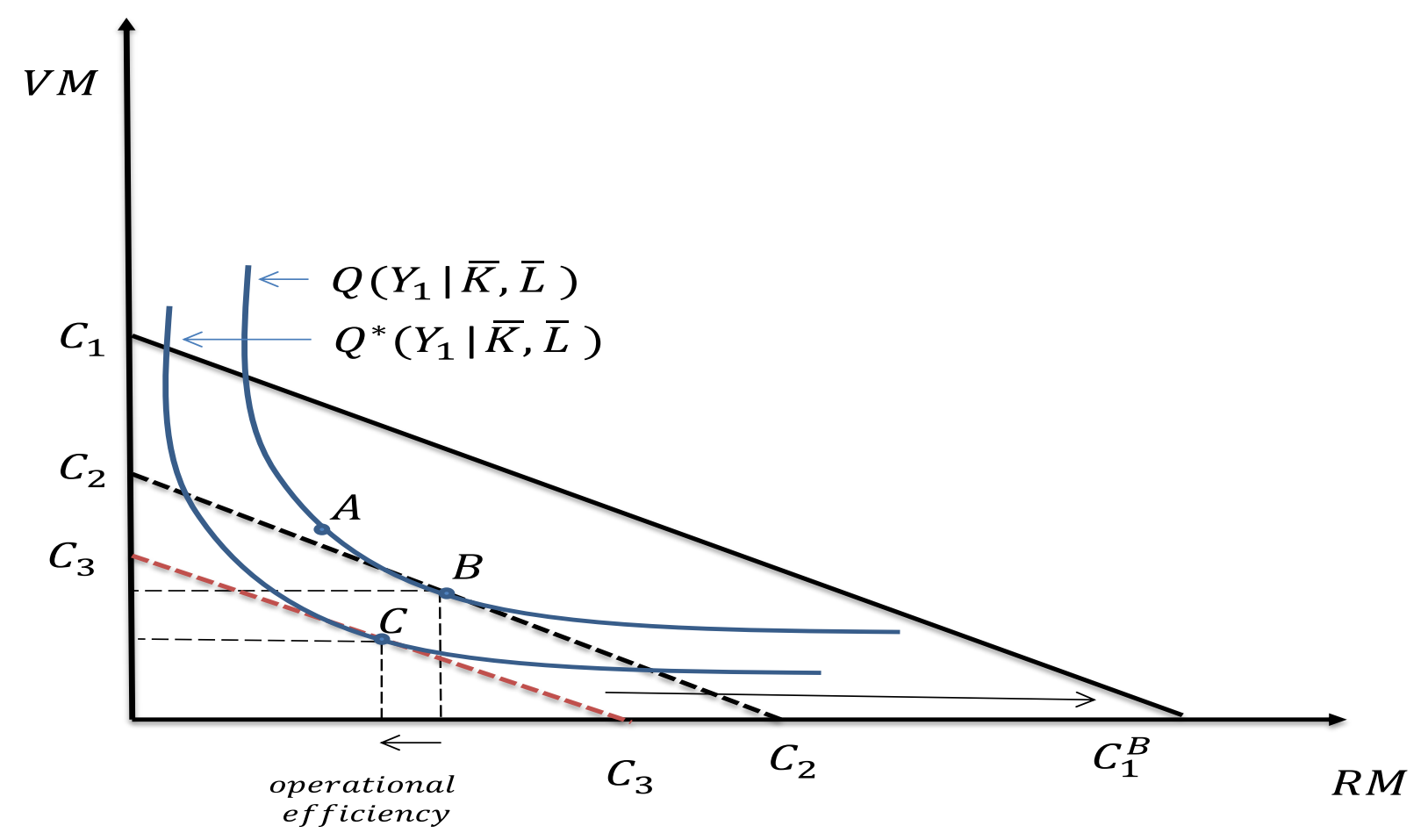

Figure 4 Reduction in resource use from improving Operational Efficiency

Figure 5 illustrates the total effect of the efficient use of resources and improvements made to the operational as the resources move from points A to C. The combined effect illustrates not only a decline in the use of virgin material along with a relatively greater dependence on recycled material but that the combined volume of input-resources needed for the same level of agricultural production is less than what was previously needed (point A). The findings in Figure 5 also illustrate the economy's capacity to cater to the increase in population growth under such circumstances. For example, if agricultural production increases (thereby increasing $\operatorname{costs}$ to $C_{4} C_{4}$ ) output increases to $\mathrm{Y}_{2}$ at point $\mathrm{D}$ on isoquant $\left(Y_{2} \mid \bar{K}, \bar{L}\right)$. For comparison purposes, at this level of production, the level of virgin material input used is identical to the level of virgin material used at point A with lower levels of production (point A). This is possible with the use of the recycled material that is now available through $\mathrm{CE}$ activity. The result demonstrates the benefits of $\mathrm{CE}$ activities, both in terms of ensuring the longevity of existing virgin materials for future generations, the reduction of environmental impact from virgin material extraction use as well as the productive use of a waste product that would have otherwise been disposed of. 


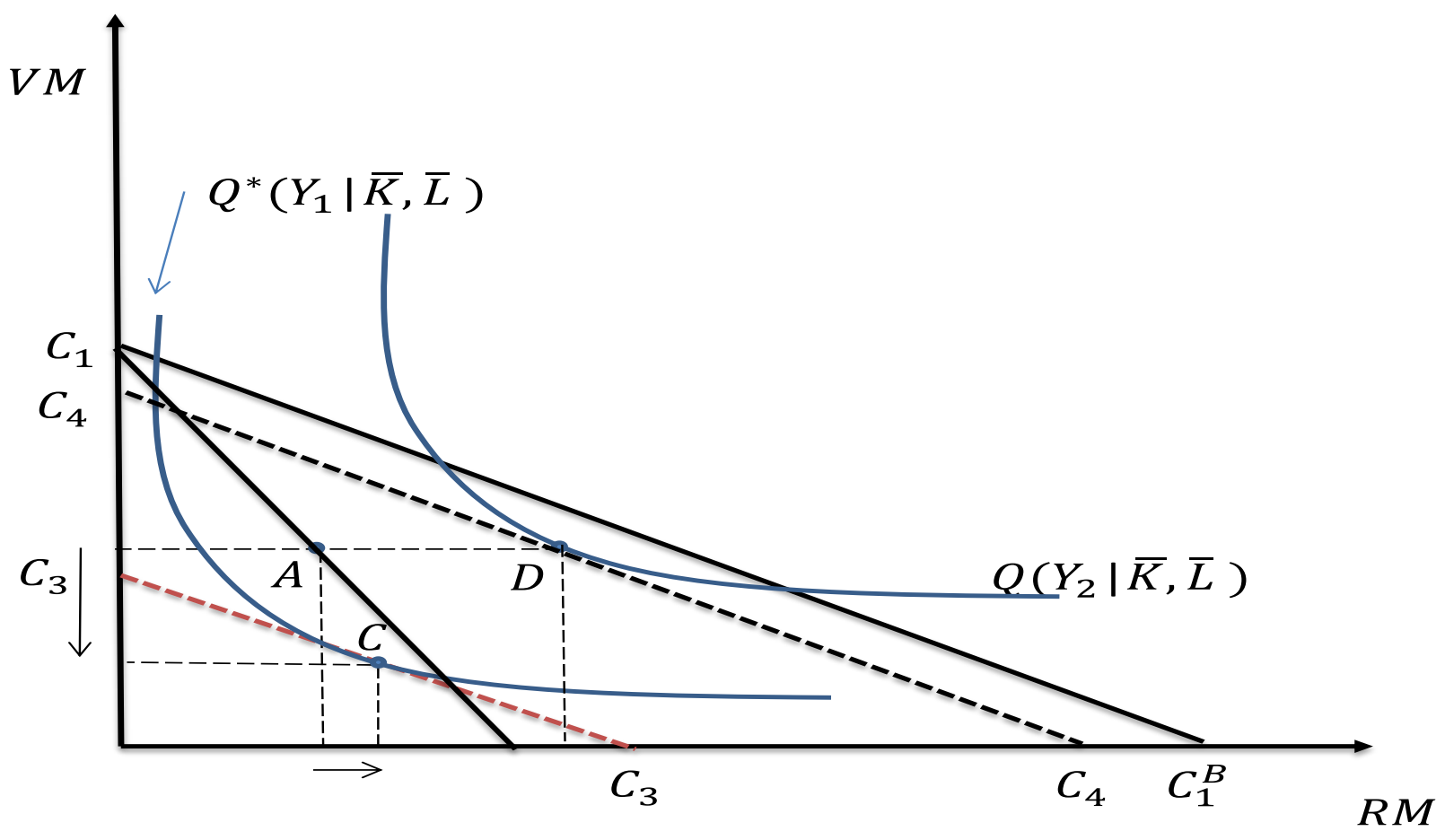

Figure 5 Productivity improvement from the combined effect of improving operational efficiency and resource recovery

Ultimately, productivity improvements from the combined effect of improving operational efficiency and resource recovery can be attained for the processing, packaging and transportation stages of a redesigned SFSC.

\section{Methodology}

The main aim of this research is to identify the inefficiencies present in the FSC through environmental impact assessment and propose a framework for redesigning the FSC using practices that improve operational efficiency and resource recovery practices for environmental sustainability. Mango is chosen as a case product. LCA using SimaPro (Version 8.4) (SimaPro, 1988 ) is performed to identify potential causes of environmental impact, including resource and operational inefficiencies. LCA is performed using a four steps that are consistent with the ISO (2006) guidelines. The four steps include: (i) 'goal and scope definition', where the goal, system description, selection of the functional unit, system boundary and assumptions made are defined; (ii) 'inventory analysis', where the data collection process and the data collected are discussed; (iii) 'methods of impact assessment,' where selected impact categories are explained; and (iv) 
results of the LCA are interpreted and the potential causes of environmental impacts are identified. Based on these findings a framework is proposed to improve environmental sustainability of FSC.

\subsection{LCA for mango FSC}

This section details the four steps in LCA for the mango FSC derived from mango pulp production industries located in Tamil Nadu, a southern state of India.

\subsubsection{Goal and scope definition}

The objective of this step is to quantify the environmental impact of the mango FSC taking into account how resources are consumed across the cultivation, processing, packaging and transportation stages of the supply chain. The consumption stage is not considered because of the difficulties in identifying consumer behaviour and the lack of available data.

\section{System description}

The life cycle of mango pulp production along with its supply chain has four distinct stages (1-4), as shown in Figure 6.

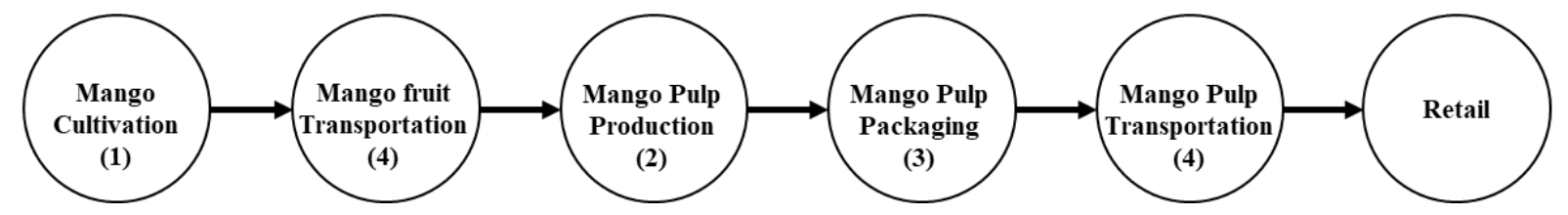

Figure 6 Existing mango FSC

The first stage involves the cultivation of the mango fruit. This includes deep ploughing, harrowing, levelling and pit preparation using machinery before planting the saplings in the field. As rainwater is the only source of irrigation in these regions, trees are planted between July and August in the ratio of 100 saplings per hectare. Fertilisers and pesticides are applied every year based on the recommended guidelines posted by the Tamil Nadu agricultural scientists (TNAU, 2017).

The second stage involves the processing of the mango fruit to produce mango pulp. While the processing steps considered here are the common practices followed by fruit processing industries in the Krishnagiri district, this can be generalised to many industrial countries as the industrial operations are standardised (Sinha et al. 2010). The raw mango fruits received from the farmers undergo several steps, as shown in Figure 7. These may include modified controlled ripening, 
sorting, washing, cutting, de-stoning, pulping and refining, evaporation and sterilisation. In the third stage, after cooling the pulp to room temperature the pulp is filled in an aseptic bag and packed in drums. The final stage involves the transportation of the mango pulp by lorries to the Indian market and by sea freight to major export markets in Europe and Arab countries. Transportation of mango from the farmers' land to mango processing industry is also considered under stage 4.

\section{The functional unit, system boundaries and assumptions}

The functional unit is the reference unit of mango pulp for which the inventory data is normalised (ISO, 2006). A pack containing $215 \mathrm{~kg}$ mango pulp is considered as the functional unit. For producing $215 \mathrm{~kg}$ of mango pulp, it consumes $430 \mathrm{~kg}$ of raw mango.

In the mango cultivation stage (see Figure 7), the inputs include fuels used for land preparation, fertilisers used for nutrient supplements, pesticides used for pest and growth management and water. Carbon-dioxide absorbed by the plant differs when compared to the quantity of carbon dioxide that is released to the environment at the end of the plant's life (Ruviaro et al., 2012). The life cycle of the vehicles and machinery utilised is not considered, however, emissions from these vehicles are included. Energy consumed and emissions produced for transportation of the harvested fruits from the farm to the processing plant is considered in the transportation stage. This includes the emissions from all transportation activities across the FSC. In the processing stage, the various inputs consumed such as chemicals, water, electricity and fuel required for processing the mango fruit for pulp are considered in this study. Resources consumed for packaging and the end-of-life of the packaging material are also covered. 


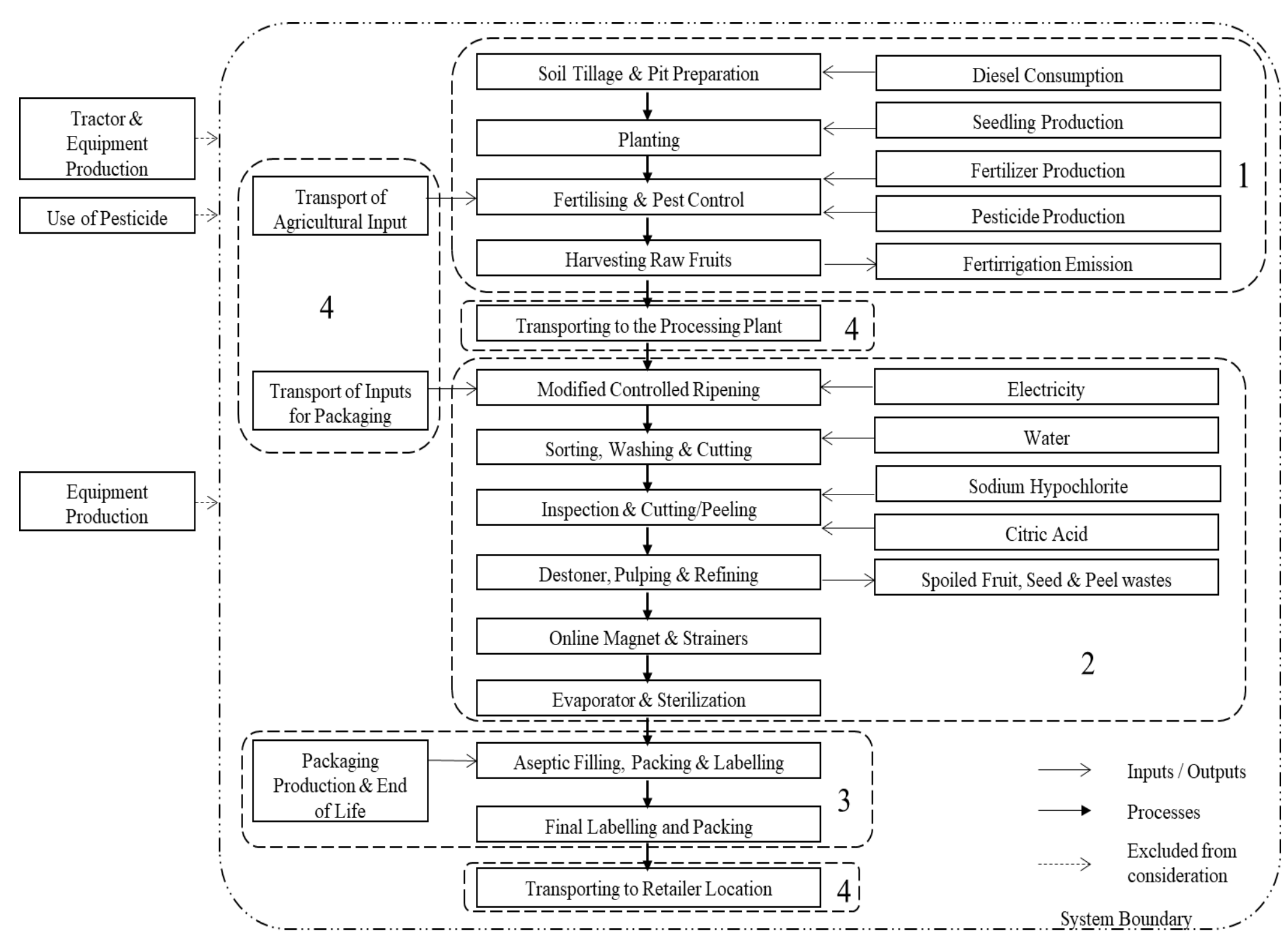

Figure 7 System boundary and process flow (the dotted line represents the four stages 1-4 within system boundary) 


\subsubsection{Inventory analysis and data collection}

The life cycle inventory analysis quantifies the amount of resource utilised and environmental releases corresponding to the system being studied in this paper (ISO, 2006). Data related to the cultivation stage of the FSC is directly gathered from farmers of the Krishnagiri and Salem districts of Tamil Nadu, (India) through questionnaires and personal interviews collected during March July 2017. Primary data related to the mango pulp production, packaging and transportation were gathered from the fruit processing industries located in the Krishnagiri district. Secondary data related to packaging materials were taken from the Eco-invent database (Frischknecht et al., 2007). Site-specific data are always used if available; otherwise, a global average is adopted from the Ecoinvent Database v3.4. Geographical coverage, time relatedness and technological coverage are considered in the data collection process (Cellura et al., 2011). Where such data is used, it is clearly stated.

\section{Mango cultivation}

It is well known in the mango industry that the yield of a mango tree increases gradually and peaks when the tree is aged between 20 to 25 years. The average yield of a mango tree throughout its lifecycle has be estimated to be between5 to 7 tons/ha/year (see Cerutti et al., 2011). The irrigation of the mango trees is entirely dependent on rainfall, and diesel-powered vehicles are typically used for tilling the soil and during the cultivation stage. Inorganic fertilisers and pesticides are used, based on the recommendations of agriculture scientists in the Tamil Nadu region. The list of input resources utilised for the cultivation phase including the emissions affecting air, water and soil quality are calculated based on the world food LCA database guidelines (Nemecek et al., 2014) and are listed in Table 1. Emissions due to pesticides are not accounted for as they are negligible compared to the impact categories analysed (Audsley and Alber, 1997). In addition, emission due to seedling production, tilling of the soil, establishing an orchard, land use change, planting tree and fertigation processes are all considered within the cultivation phase.

The amount of each input used per functional unit is summarised in Table 1. 
Table 1 Inventory data for cultivation, pulp production and packaging stage

\begin{tabular}{llll}
\hline Stages & Input & \multicolumn{2}{l}{ Amount per functional unit } \\
\hline Mango Cultivation & Diesel & 0.0004 & $\mathrm{litr}$ \\
& Nitrogen & 5.9812 & $\mathrm{~kg}$ \\
& Phosphorous as $\mathrm{P}_{2} \mathrm{O}_{5}$ & 5.9812 & $\mathrm{~kg}$ \\
& Potassium as $\mathrm{K}_{2} \mathrm{O}$ & 5.9812 & $\mathrm{~kg}$ \\
& Insecticides & 0.1178 & $\mathrm{~kg}$ \\
Mango Pulp Production & Diesel & 0.1433 & $\mathrm{litre}$ \\
& Water & 143.4 & $\mathrm{litre}$ \\
& Sodium hypochlorite & 0.0478 & $\mathrm{~kg}$ \\
& Electricity & 7.8833 & $\mathrm{kWh}$ \\
Mango Pulp Packaging & Citric acid & 0.645 & $\mathrm{~kg}$ \\
& Steam & 1.72 & $\mathrm{~kg}$ \\
& Electricity & 0.086 & $\mathrm{kWh}$ \\
Transportation Stage & LDPE film & 630 & $\mathrm{gram}$ \\
& MS Drum (Empty) & 17 & $\mathrm{~kg}$ \\
& Transoceanic & 1930 & $\mathrm{tkm}$ \\
& Transport to port & 54.2 & $\mathrm{tkm}$ \\
& Mango transport from Farmers & 0.206 & $\mathrm{tkm}$ \\
& Packing material transport & 3.97 & $\mathrm{tkm}$ \\
& Fertiliser transport & 0.0004 & $\mathrm{tkm}$ \\
\hline
\end{tabular}

\section{Mango pulp production}

In the mango pulp production stage, citric acid is used in modified controlled ripening of mango fruit to ensure equal ripening of mango fruits. Sodium hypochlorite is then used in the cleaning of mango fruit. All the machinery used in this process is powered by electricity and diesel-powered electricity generators. The quantity of all these resources consumed per functional unit is given in Table 1.

\section{Mango pulp packaging}

The use of interviews provided the necessary data on the packaging during the process of fruit processing. Packaging materials used for one drum $(215 \mathrm{~kg})$ of mango pulp is included here. The electricity and steam used for the packaging process are calculated corresponding to the functional unit and listed in Table 1. Secondary data related to packaging materials were taken from the Ecoinvent database (Frischknecht et al., 2007). The distance required to transport the drums and the low-density polyethylene (LDPE) film used is also considered. 


\section{Mango and mango pulp transportation}

There are two major stages in the transport of the mango product. The first involves transporting the mango fruits from the farm to the processing plants. A total of $45 \%$ of all mangoes are sourced from local farmers, 30\% from Karnataka state and 25\% from Andhra Pradesh state, with an average transportation distance of $100 \mathrm{~km}, 180 \mathrm{~km}$ and $500 \mathrm{~km}$ respectively. The second stage of the transportation involves moving the packaged fruit pulp to the retail point of sale. Transportation to the loading docks at Chennai for export to European countries is considered in this stage. Secondary data related to transportation processes were taken from the Ecoinvent database (Frischknecht et al., 2007). The transportation of fertiliser and packaging material is also accounted for in this stage.

Based on the data collected on inputs, a model is developed in the SimaPro software. A model corresponding to each stage (cultivation, processing, packaging and transportation) is developed based on all the resources consumed. Finally, a solution to the developed model is provided using an impact assessment method discussed in the next section.

\subsubsection{Methods of impact assessment}

The inventory data collected is used in the impact assessment phase to calculate the environmental effects (ISO, 2006). The impact categories recommended by the international reference life cycle data system handbook (Wolf et al., 2010) are used. The CML-IA impact assessment method and its eight impact categories developed by the Centre of Environmental Science (Guinée, 2002) of Leiden University in the Netherlands form the basis of measurement. These impact categories are selected such that it measures the FSC's impact on human health, natural environment and natural resources (ISO, 2006). These impact categories are also commonly used in literature for LCAs of FSCs (Manfredi and Vignali, 2014; Strazza et al., 2015). The impact categories mentioned are recognised as: global warming potential (GWP100a), human toxicity (HT), fresh water aquatic ecotoxicity (FW), marine aquatic ecotoxicity (MAE), terrestrial ecotoxicity (TE), photochemical oxidation (PO), acidification (AC) and eutrophication (EU). The water footprint assessment of the system is based on Hoekstra et al., (2012).

\subsubsection{Interpretation of results}

In this subsection, the results obtained from the LCA are analysed and a discussion on the major contributor of environmental impact across each stage follows. 


\section{Environmental Impact of mango FSC}

Table 2 shows the environmental impact corresponding to a $215 \mathrm{~kg}$ pulp drum that is taken as the functional unit. Environmental impacts are represented using different impact categories.

Table 2 Environmental impacts corresponding to different stages of mango FSC

\begin{tabular}{lllllll}
\hline $\begin{array}{l}\text { Impact } \\
\text { Categories }\end{array}$ & Unit & Total & Cultivation & $\begin{array}{l}\text { Pulp } \\
\text { Production }\end{array}$ & $\begin{array}{l}\text { Pulp } \\
\text { Packaging }\end{array}$ & Transport \\
\hline GWP100a & kg CO2 eq & 143.6948 & 42.9594 & 15.8203 & 51.9237 & 32.9913 \\
HT & kg 1,4-DB eq & 1277.0140 & 26.8489 & 2.6717 & 1239.6429 & 7.8505 \\
FW & kg 1,4-DB eq & 8.3776 & 6.7335 & 0.2097 & 1.1764 & 0.2580 \\
MAE & kg 1,4-DB eq & 53664.40 & 7646.98 & 11826.55 & 31153.12 & 3037.73 \\
TE & kg 1,4-DB eq & 2.8338 & 1.3078 & 0.0241 & 1.4740 & 0.0279 \\
PO & kg C2H4 eq & 0.0403 & 0.0095 & 0.0043 & 0.0088 & 0.0178 \\
AC & kg SO2 eq & 1.2086 & 0.2537 & 0.1132 & 0.3462 & 0.4955 \\
EU & kg PO4- eq & 0.4322 & 0.3452 & 0.0127 & 0.0264 & 0.0478
\end{tabular}

Table 2 shows that the packaging stage contributes towards the maximum environmental impact in almost all the impact categories. This result can be compared with the those findings reported by Manfredi and Vignali (2014) and Borghi et al. (2014), for the tomato puree production industry. Borghi et al., (2014), and Manfredi and Vignali, (2014) also found that the packaging stage produced the maximum environmental impact in the tomato supply chain. After packaging, the cultivation stage in the mango FSC has the highest environmental impact across most impact categories, followed by transportation and pulp production.

\section{Mango cultivation}

The cultivation stage of the mango life cycle has a significant impact on the environment, as shown in 
Table 3. 
Table 3 Environmental impacts corresponding to inputs consumed at each stage of mango FSC

\begin{tabular}{|c|c|c|c|c|c|c|c|c|c|c|c|c|c|c|c|c|c|c|c|c|c|c|c|}
\hline \multirow[b]{2}{*}{ 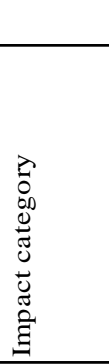 } & \multirow[b]{2}{*}{$\overrightarrow{\tilde{5}}$} & \multicolumn{7}{|c|}{ Cultivation Stage } & \multicolumn{4}{|c|}{ Processing Stage } & \multicolumn{6}{|c|}{ Packaging Stage } & \multicolumn{5}{|c|}{ Transportation Stage } \\
\hline & & 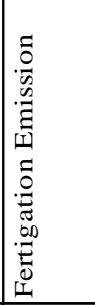 & 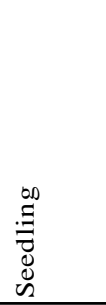 & $\begin{array}{l}\stackrel{\infty}{\Xi} \\
\stackrel{\Xi}{\Xi} \\
\frac{\vec{\sigma}}{\alpha}\end{array}$ & $\begin{array}{l}\stackrel{0}{\Xi} \\
\stackrel{\Xi}{ \pm} \\
\Sigma\end{array}$ & 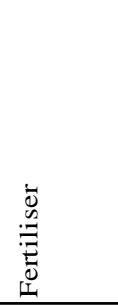 & 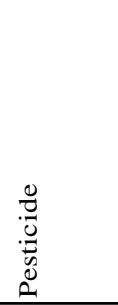 & 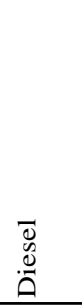 & 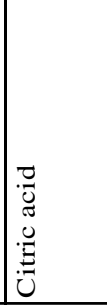 & $\begin{array}{l}\bar{D} \\
\stackrel{D}{D} \\
\vec{D}\end{array}$ & 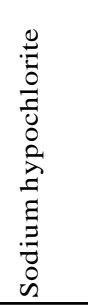 & 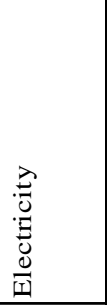 & 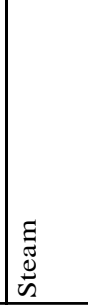 & 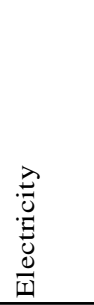 & $\begin{array}{l}\bar{U} \\
\bar{U}\end{array}$ & âd & 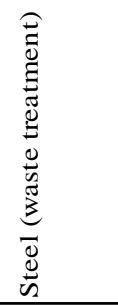 & 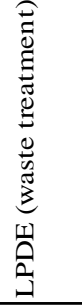 & 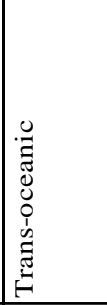 & 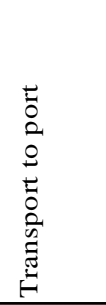 & 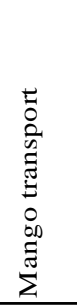 & 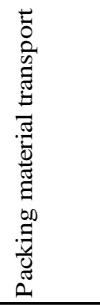 & 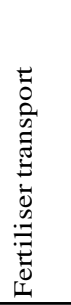 \\
\hline GWP100a & $\mathrm{kg} \mathrm{CO} 2 \mathrm{eq}$ & 16.589 & 3.208 & 2.163 & 3.163 & 14.232 & 2.413 & 1.193 & 4.587 & 0.449 & 0.040 & 10.744 & 0.282 & 0.117 & 78.784 & 1.843 & -28.054 & -1.049 & 17.209 & 8.954 & 0.040 & 6.788 & 0.000 \\
\hline HT & $\mathrm{kg} 1,4-\mathrm{DB}$ eq & 20.232 & 0.654 & 0.302 & 0.226 & 1.999 & 3.369 & 0.068 & 1.223 & 0.023 & 0.005 & 1.421 & 0.033 & 0.016 & 1248.680 & 0.109 & -9.197 & 0.002 & 5.086 & 2.289 & 0.008 & 0.469 & 0.000 \\
\hline FW & $\mathrm{kg} 1,4-\mathrm{DB}$ eq & 1.235 & 1.396 & 0.465 & 0.361 & 3.195 & 0.070 & 0.012 & 0.179 & 0.002 & 0.000 & 0.029 & 0.003 & 0.000 & 1.261 & 0.006 & -0.094 & 0.000 & 0.132 & 0.087 & 0.000 & 0.039 & 0.000 \\
\hline MAE & $\mathrm{kg} 1,4-\mathrm{DB}$ eq & 814.710 & 2044.730 & 283.360 & 274.590 & 3143.490 & 1051.980 & 34.090 & 2574.530 & 12.370 & 23.940 & 9215.690 & 75.360 & 100.530 & 39291.000 & 302.390 & -8656.170 & 39.030 & 2052.040 & 659.600 & 2.210 & 323.870 & 0.002 \\
\hline $\mathrm{TE}$ & $\mathrm{kg} 1,4-\mathrm{DB}$ eq & 0.503 & 0.047 & 0.046 & 0.129 & 0.575 & 0.004 & 0.004 & 0.014 & 0.000 & 0.000 & 0.010 & 0.000 & 0.000 & 1.514 & 0.001 & -0.041 & 0.000 & 0.018 & 0.007 & 0.000 & 0.002 & 0.000 \\
\hline PO & $\mathrm{kg} \mathrm{C} 2 \mathrm{H} 4 \mathrm{eq}$ & 0.000 & 0.001 & 0.000 & 0.001 & 0.006 & 0.001 & 0.000 & 0.001 & 0.000 & 0.000 & 0.003 & 0.000 & 0.000 & 0.028 & 0.000 & -0.019 & 0.000 & 0.014 & 0.001 & 0.000 & 0.003 & 0.000 \\
\hline $\mathrm{AC}$ & $\mathrm{kg} \mathrm{SO} 2 \mathrm{eq}$ & 0.081 & 0.018 & 0.015 & 0.015 & 0.094 & 0.023 & 0.009 & 0.030 & 0.005 & 0.000 & 0.078 & 0.001 & 0.001 & 0.452 & 0.007 & -0.113 & -0.003 & 0.436 & 0.034 & 0.000 & 0.026 & 0.000 \\
\hline $\mathrm{EU}$ & kg PO4- eq & 0.285 & 0.003 & 0.009 & 0.010 & 0.032 & 0.004 & 0.002 & 0.006 & 0.001 & 0.000 & 0.006 & 0.000 & 0.000 & 0.037 & 0.001 & -0.011 & 0.000 & 0.037 & 0.006 & 0.000 & 0.005 & 0.000 \\
\hline
\end{tabular}


Fertilisers used as a nutrient supplement should be based on the condition of the soil and the crop being grown. The use of fertilisers over and above that is necessary alters the properties of soil resulting in adverse environmental impacts. As shown in 
Table 3, the production of fertilisers causes a maximum impact on the environment in most of the categories with PO (64.93\%), FW (47.44\%), MAE (41.11\%) and AC (36.99\%). Among the fertilisers used, the use of potassium causes maximum environmental impact. In addition to this, fertigation emission has a high environmental impact through EU (82.6\%), thus heavily affecting human health with $20.23 \mathrm{~kg}$ 1, 4-dichlorobenzene equivalent measure of HT. In addition, the use of pesticides on the farm has a significant environmental impact due to PO (14.79\%), MAE (13.75\%) and HT (12.54\%).

\section{Mango pulp production}

A considerable amount of resources such as energy, water and chemicals are used during the processing stage of the mango supply chain, which directly impacts the environment. Due to the delay in mango supply from farmers and inefficient production plans, the facilities have not been utilised at capacity resulting in high utilisation of resources. As shown in 
Table 3, use of electricity for pulp production has a high impact on the natural ecosystem and human health, as non-renewable natural resources (such as coal) are used for electricity generation to run the processing machines and for the production of the machinery itself. Electricity consumption contributes $67.92 \%$ to FWP100a, 53.19\% to HT, $77.92 \%$ to MAE, $68.85 \%$ to AC and $66.47 \%$ to PO. Additionally, when the fruits are ripened artificially, regardless of the maturity of the fruit, the same level of treatment for ripening is given. This, in turn, alters the desired property of mango pulp produced. At this point, the options available are to either add citric acid to the pulp or reject the entire quantity produced. The use of citric acid has the most significant environmental impact in the processing stage after electricity, with FW (85.14\%), TE (59.44\%) and EU (43.8\%). Similarly, the water footprint index is estimated to be $0.73 \mathrm{~m}^{3}$, which corresponds to the amount of water consumed in the processing stage for fruit washing.

Besides the resources consumed for processing of the mango pulp, the mango fruit processing industries produce an almost equal amount of wastage (peel, seeds, and damaged fruits) as the final product by weight. In India, most of this FW goes into landfill, not only resulting in the disposal of a useful resource but also polluting the soil as a result of the concentrate of substances present in the waste.

\section{Mango pulp packaging}

The packaging stage of the supply chain has the maximum environmental impact in most of the impact categories, as compared with all the other stages of the mango FSC. The quantity of steel consumed to manufacture the packaging drums and the low-density polyethene (aseptic plastic bags) used in the packing of mango pulp are the major causes of the environmental impact of this stage. The packed drum is mostly exported to Arabian and European countries, where the containers are scrapped after taking out the mango pulp. Thus, the maximum value is not extracted from this packaging material, resulting in a high impact on the environment. Table 3 shows the values corresponding to the impact categories. In addition, the water footprint index for the water consumed in the packing stage is calculated as $44 \mathrm{~m}^{3}$ based on the water footprint assessment method (Hoekstra et al., 2012).

Steel as an input resource is the major contributor to environmental impact in this packaging stage, with more than $90 \%$ contribution among the majority of impact categories. Scrapping the steel 
drum containers creates value and reduces the environmental impact by $67.39 \%$ PO, 34.63\% GWP100a, 29.07\% EU, 24.38\% AC, and 21.76\% MAE categories.

\section{Mango and Mango pulp transportation}

Transportation is involved in all stages of the supply chain. In the cultivation stage it is used for procuring fertilisers, pesticides and other inputs; in the processing stage for procuring the chemicals and for transporting mangoes from farms to processor; in the packaging stage for obtaining packaging materials from local markets; and in the transportation stage where packed mango pulp drums are transported domestically and internationally. Across all stages, the transportation operations are not performed in an optimised way, either by using optimal vehicle capacity or load carried, resulting in environmental impacts. The distance the pulp is transported to reach the customer location correlates to maximum emissions into the environment with $\mathrm{AC}$ (87.92\%), EU (77.40\%), PO (77.08\%), TE (65.52\%) and FW (51.28\%) as shown in 
Table 3. In addition, the transport of packed pulp from the processing centres to ports has a significant impact on the environment.

In Figure 8 we consolidates the findings by outlining the potential causes of environmental impact at each of the four stages of the mango FSC. Both operational and resource inefficiency practices across the mango FSC are also illustrated in Figure 8.

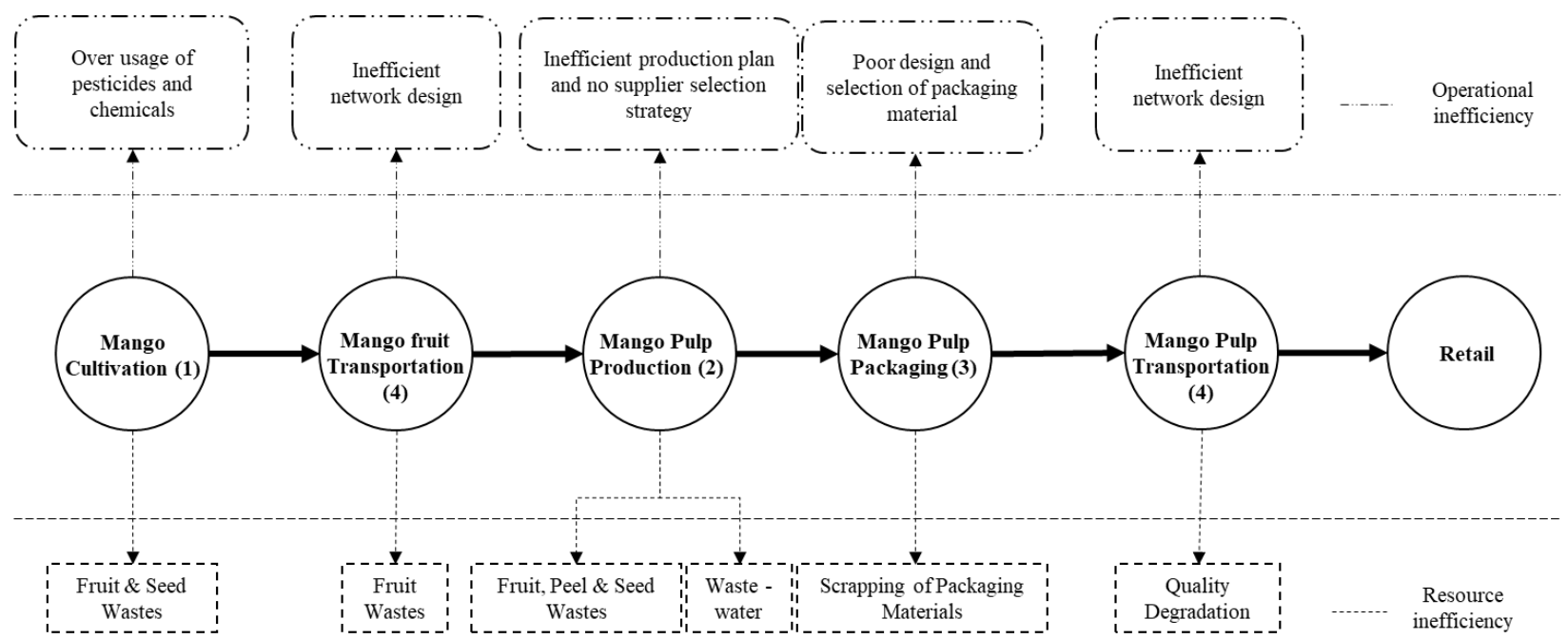

Figure 8 Potential causes of environmental impact at each stage of mango FSC

In direct response to this, the application of operational efficiency improvement practices and resource recovery practices would address these inefficiencies and help in achieving environmental sustainability. By improving operational efficiency in a mango FSC, the amount of waste that occurs may be reduced, thus limiting the amount of waste that needs to be recovered.

The following section outlines the development of a framework that shows how the existing mango FSC can be redesigned that would lessen the environmental impacts and contribute to improved economic and social benefits.

\section{Development of a framework for sustainable mango FSC by analysing resources}

The LCA analysis illustrates how each stage of the mango FSC has a significant impact on the environment. Environmental impact is also an indication of inefficiency in operations and resources use (Ding et al., 2016). As a way to address these inefficiencies using the proposed conceptual framework given in Figure 2, a suggestion for redesigning of the mango FSC is given. A review of the literature provided a list of practices to improve operational efficiency and resource 
recovery that help in improving operational efficiencies and resource recovery mechanisms. Drawing on these identified practices, the redesign of the mango FSC is illustrated in Figure 9 and detailed in Table 4. In addition, the wastages occurring in existing mango FSC are identified and ways to reduce this are discussed.

\section{Operational efficiency improvement and resource recovery practices for mango cultivation stage}

In developing countries, more than $70 \%$ of available freshwater is used in agriculture due to inefficient agriculture practices, resulting in scarcity of water in many of the states of India as well as having a significant environmental impact on other areas dependent on this water use (Bagh, 2005; Dhawan, 2017). To address this, precision agriculture (Adekunle I.O, 2013) and integrated production systems (Parajuli et al., 2018) can be adopted to increase crop yield while reducing the amount of resource consumed as per Figure 4. Precision agriculture systems control the amount of inputs consumed such as water, fertiliser and other chemicals thereby limiting the adverse effects on the soil condition and crop yield. An integrated production system considers ecological interactions alongside the land use systems to ensure efficient nutrient cycling, improving soil nutrients, enhancing biodiversity and preserving natural resources (Figure 4) in the agricultural ecosystem (Chen et al., 2011; Lemaire et al., 2014).

Collaboration with the supply chain entities can assist in the planning of cultivation activities and harvesting dates (Dos Santos and Smith, 2008) in order to reduce the uncertainty of demand for the mango fruit. Additionally, post-harvest waste can be avoided by following the maturity indices proposed by the Ministry of Agriculture (2013). By following such maturity indices, damaged mangoes can be treated separately for value creation, which in turn reduces the consumption of virgin material used in the supply chain (consistent with Figure 3).

Operational efficiency improvement and resource recovery practices for mango pulp production stage

In the FSC, the matching of demand and supply is always a major task (Diabat et al., 2012). The choice of suppliers who have flexibility in cultivation has a significant impact on the resilience of the supply chain (Kamalahmadi and Mellat-Parast, 2015). Therefore, supplier selection should be undertaken taking into account all the critical factors using multi-criteria approaches (Govindan et al., 2017). In addition, building long-term relationships with suppliers reduces risk around input 
supply and thereby results in better utilisation of facilities and resources at the processing plant and reduction in production cost. While ensuring continuous supply, it is also important to plan inventory decisions and production schedules consistent with the supply chain strategy in place to limit unnecessary uncertainties. Furthermore, non-value-added activities can be eliminated in the processing plant through the implementation of lean manufacturing tools such as value stream mapping, continuous improvement, 5S and total productive maintenance (Rother and Shook, 2003).

Ripening of mature and immature fruits alters the required properties of the mango pulp. A systematic grading of fruits will avoid this variation in the fruit ripening process (see similar suggestions by Ministry of Agriculture, 2013). To manage the waste generated during the process of mango pulp production, a sustainable way of disposing of the fruit waste should be adopted in a way consistent with the suggested by Anbazhagan, 2016; Mirabella et al., 2014. For example, the combination of mango seed kernel extract and oil contains high amounts of antioxidants, which can be used as a natural antioxidant with antimicrobial properties in other foods (Mirabella et al., 2014). In addition, the bio-fertiliser that is produced from the recycled material can be used back in the cycle to reduce the consumption of virgin materials (see Figure 3). Currently, the Indian government is also encouraging the use of bio-wastes to produce organic manure and biogas under the Capital Investment Subsidy Scheme of the National Mission for Sustainable Agriculture (NMSA) program (Ministry of Agriculture, 2013). It is noted that water consumed in the processing stage is also capable of being completely recycled. In this way, following a CE and operations management based practice, waste and virgin material consumption will reduce; simultaneously reducing environmental impacts, creating job opportunities and economic benefits consistent with the conclusions presented in Figure 3 and Figure 4. Evidently, virgin and recycled materials saved by these alternative approaches can be used to further increase production levels (see Figure 5) in order to meet the needs of a growing world population.

Operational efficiency improvement and resource recovery practices for mango pulp packaging stage

Proper selection and optimal design of the packaging material can also reduce the environmental impact significantly (Accorsi et al., 2014; Manfredi and Vignali, 2014). As Manfredi and Vignali (2014) highlighted, reducing the weight of the material by $20 \%$ results in a $15 \%$ to $20 \%$ reduction 
in the environmental impact. Based on the life cycle analysis done on the packaging materials in fruits and fruit pulps, reuse of the packing material is found to be the best option for an end-of-life strategy (Accorsi et al., 2015, 2014). It is crucial, therefore, that the packaging material is designed taking into account the end-of-life conditions.

Operational efficiency improvement and resource recovery practices for mango transportation stage

The industry considered in this case study procures more than half the quantity of mangoes from other states, which involves transportation over long distances, creating a degree of supply uncertainty, and causing significant emissions to the environment. Sourcing from local farmers would reduce this uncertainty in supply and emission (Lehtinen, 2012). In local sourcing, transport distances can be decreased through proper mapping and documentation of supplier locations and their capacity. Coordination and simplification of logistical decisions in the supply chain through optimisation techniques will help in reducing the resources consumed and the corresponding environmental impacts (Etemadnia et al., 2015).

The following Table 4 summarises the above discussion of Operational efficiency improvement and resource recovery practices for addressing resource and operational inefficiency in a mango FSC. The potential causes of environmental impacts are ranked based on the result of an LCA.

Table 4 Summary of best practices for achieving environmental sustainability in mango FSC

\begin{tabular}{lllll}
\hline Stages & $\begin{array}{l}\text { Causes of } \\
\text { Environmental } \\
\text { Impact }\end{array}$ & $\begin{array}{l}\text { Impact- } \\
\text { wise } \\
\text { Ranking } \\
\text { based on } \\
\text { LCA }\end{array}$ & $\begin{array}{l}\text { Operational Efficiency } \\
\text { Improvement }\end{array}$ & Resource Recovery \\
$\begin{array}{llll}\text { Cultivation } \\
\text { Stage }\end{array}$ & $\begin{array}{l}\text { Fertigation } \\
\text { Emission }\end{array}$ & 2 & $\begin{array}{l}\text { Adoption of precision agriculture } \\
\text { practices regulates the } \\
\text { overconsumption of fertilisers }\end{array}$ & $\begin{array}{l}\text { Integrated production } \\
\text { system reduces/ } \\
\text { eliminates the } \\
\text { requirement of fertiliser } \\
\text { (Al Shamsi et al., 2018) }\end{array}$ \\
& Seedling & 3 & - & $\begin{array}{l}\text { Reuse of soil and } \\
\text { seedling container }\end{array}$ \\
& Fertiliser & 1 & - & $\begin{array}{l}\text { Eliminating usage of } \\
\text { Non-organic fertilisers }\end{array}$ \\
& Pesticide & 4 & - & $\begin{array}{l}\text { Adoption of an } \\
\text { integrated production } \\
\text { system reduces the }\end{array}$
\end{tabular}


requirement of pesticides (Al Shamsi et al., 2018)

Fruit wastes $\quad$ - $\quad$ Following maturity indices help in picking well-matured fruits (Ministry of Agriculture, 2013).

\begin{tabular}{|c|c|c|}
\hline \multirow{6}{*}{$\begin{array}{l}\text { Processing } \\
\text { Stage }\end{array}$} & Citric acid & 2 \\
\hline & Diesel & 3 \\
\hline & $\begin{array}{l}\text { Sodium } \\
\text { hypochlorite }\end{array}$ & 4 \\
\hline & Electricity & 1 \\
\hline & Water & - \\
\hline & $\begin{array}{l}\text { Wastage of } \\
\text { fruits, peels and } \\
\text { seeds }\end{array}$ & - \\
\hline
\end{tabular}

Pulp Packaging Steam

Stage
Extraction of nutrients from fruit waste \& composting of wastes to produce manures (Ajila et al., 2007; Mirabella et al., 2014).

Identification of optimal quantity of citric acid that needs to be added

Value stream mapping can help identify non-value added and reduce resource consumption (Rother and Shook, 2003).

Identification of optimal quantity of sodium hypochlorite that needs to be added
Use of renewable and recyclable energy resources (Ngoc and Schnitzer, 2009)

Recycling \& reuse of waste water (Vergine et al., 2017).

Using seeds for seedling production

Extraction of nutrients from fruit waste \& composting of wastes to produce manures (Ajila et al., 2007; Mirabella et al., 2014).

Use of renewable and recyclable energy resources (Ngoc and Schnitzer, 2009)

Use of renewable and recyclable energy resources (Ngoc and Schnitzer, 2009)

Steel 1 Optimal design \& selection of packaging material (Manfredi and Vignali, 2014).

LDPE 2
Optimal design \& selection of packaging material (Manfredi and Vignali, 2014).
Reuse / remanufacture / recycle (Ghisellini et al., 2016; Zeng et al., 2017).

Reuse / remanufacture / recycle (Ghisellini et al., 2016; Zeng et al., 2017). 


\begin{tabular}{|c|c|c|c|}
\hline \multirow{5}{*}{$\begin{array}{l}\text { Transportation } \\
\text { Stage }\end{array}$} & Trans-oceanic & 1 & - \\
\hline & $\begin{array}{l}\text { Transportation } \\
\text { of mango pulp } \\
\text { to port }\end{array}$ & 2 & $\begin{array}{l}\text { Network optimisation considering } \\
\text { full truckload (Ghisellini et al., } \\
\text { 2016) }\end{array}$ \\
\hline & $\begin{array}{l}\text { Mango } \\
\text { transportation }\end{array}$ & 4 & $\begin{array}{l}\text { Proper mapping and documentation } \\
\text { of supplier location and their } \\
\text { capacity and scheduling mango } \\
\text { procurement. }\end{array}$ \\
\hline & $\begin{array}{l}\text { Packing } \\
\text { material } \\
\text { transport }\end{array}$ & 3 & $\begin{array}{l}\text { Local Sourcing (Borghi et al., } \\
\text { 2014). }\end{array}$ \\
\hline & $\begin{array}{l}\text { Fertiliser } \\
\text { transport }\end{array}$ & 5 & $\begin{array}{l}\text { Local sourcing of agricultural input } \\
\text { and planned procurement (Borghi } \\
\text { et al., 2014). }\end{array}$ \\
\hline
\end{tabular}

Based on the above discussion, a framework that address both operational and resource inefficiency in the mango FSC is proposed (Figure 9). This redesigned FSC is sustainable on three dimensions - economic, social and environmental - perspectives.

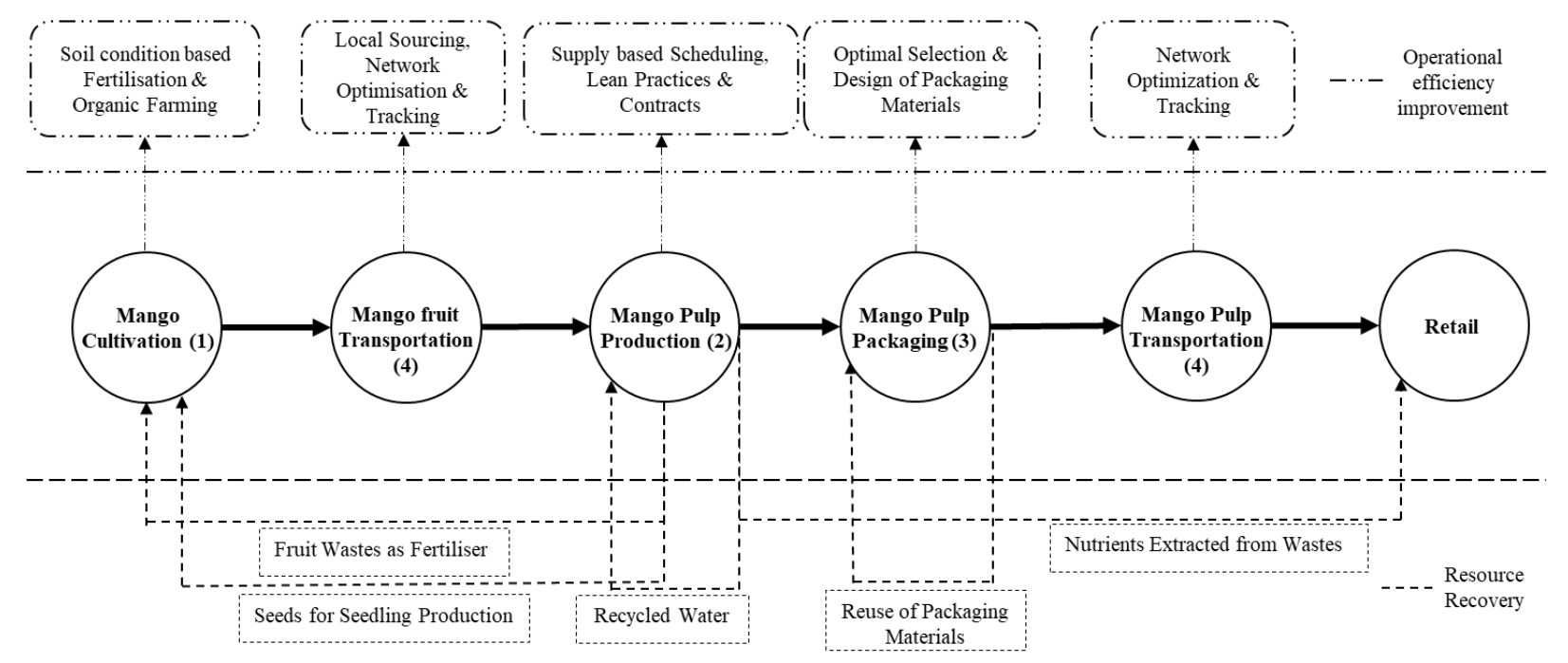

Figure 9 Redesigned sustainable mango FSC framework

This sustainable mango FSC framework shows how operational issues at every stage of the supply chain can be addressed using appropriate tools. Practices/tools that address mainly operational issues are illustrated at the top of Figure 10 and resource recovery issues addressed are illustrated at the bottom of Figure 10. The arrows used show how the waste generated can be put back in the cycle across the various stages of the FSC. Operational efficiency improvement practices ensures 
the optimal allocation of resources that, in turn, reduces the amount of waste generated. For example, the optimal design of the transportation network reduces the distance travelled and the delivery time for food products, reducing food wastage by preserving the quality of the product delivered, as highlighted in Figure 4. Further, high levels of waste are best addressed through the reuse and recycling of waste. Thus, food waste in any form at any stage of the mango FSC can be used for value creation through appropriate processes and reintegrated back in the cycle (Ajila et al., 2007) (Figure 3).

\section{Sensitivity analysis of resource usage and environmental impact}

Sensitivity analysis is performed to identify the potential resource that can provide improvements in processes and reduce any adverse environmental impacts (Garofalo et al., 2017; Manfredi and Vignali, 2014).

Based on the result of an LCA, packaging has been identified as a critical stage causing a most environmental impact in a mango FSC. Optimal design and selection of packaging material have been suggested as a way of reducing significant environmental impact. In validating this suggestion, sensitivity analysis is performed on $10 \%$ weight reduction of packaging material, to identify the potential for reducing environmental impact. The result of this analysis showed that there is a $9-10 \%$ reduction in the environmental impact across all the impact categories as shown in Figure 10. This finding aligns with that of Manfredi and Vignali, (2014).

Furthermore, the transportation stage resulted in significant environmental impact across all the impact categories as shown in Table 2. To address this operational inefficiency, network optimisation, reducing the number of trips and local sourcing, has been suggested as a practical strategy. Validating the impact of this strategy, sensitivity analysis of a $10 \%$ reduction in transportation distance across all different transportation methods involved is performed. Figure 10 shows the $\%$ reduction in environmental impact across all the considered impact categories corresponding to this transportation distance reduction.

Results of these two categories substantiate reducing environmental impact through incorporating the tools and practices suggested in Figure 9 and Table 4. With this result and the evidence from the literature (Garofalo et al., 2017; Manfredi and Vignali, 2014), it can be asserted that addressing resource and operational inefficiency will help in reducing the environmental impact. To this 
effect, sensitivity analysis corresponding to all other parameters may be performed and its potential for reducing environmental impact subsequently analysed.

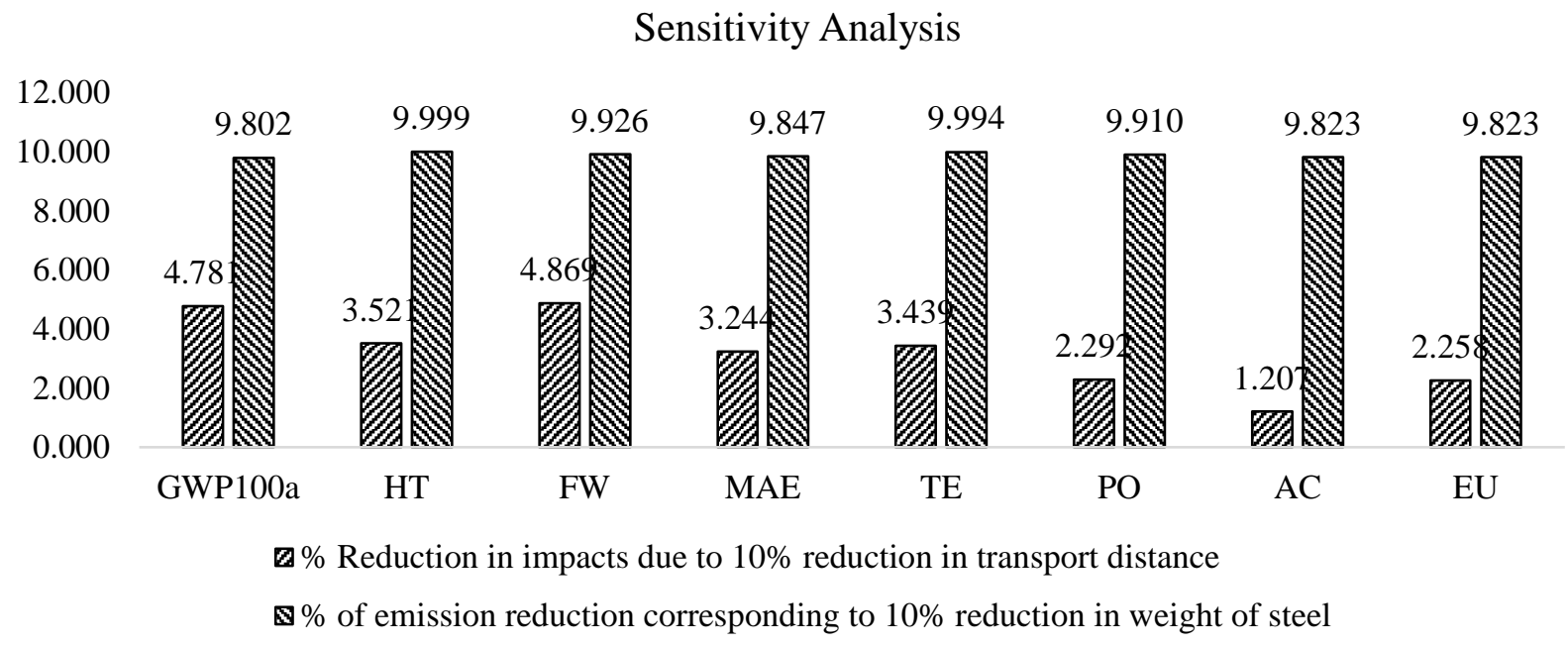

Figure 10 Sensitivity analysis

Hence, the inefficiencies and corresponding environmental impact can be addressed through operational efficiency improvement and resource recovery practices.

\section{Managerial implications and concluding remarks}

Increasing global food demand, alongside resource consumption rates put enormous pressure on the available but limited natural resources. Only by making the FSC more sustainable by ensuring a reduction in waste, it is possible to address the increasing food demand. Following a systematic review method to analyse the literature, the LCA methodology is used to assess the environmental impacts of the current Indian mango FSCs. Based on the inefficiencies identified from the LCA results, an SFSC framework is proposed that can be used to redesign any FSC - not only having the capacity to be resource-efficient, but sustainable as well.

This study has identified limitations as well as implications for both researchers and FSC managers in order to attain sustainable practices across agribusiness. Firstly, the redesigned sustainable mango FSC would benefit from implementation in real time helping to quantify economic, environmental and social improvements. One could also apply the proposed conceptual framework (Figure 2) to other food products and associated supply chains thereby revealing the operational and resource inefficiencies within those FSCs. Adopting this conceptual framework to other 
industries beyond food (e.g. manufacturing) is also possible using this approach wherein opportunities for improving operational efficiency and resource recovery for environmental sustainability can be identified in similar way.

Using the dotted line in the conceptual framework in Figure 2, one could assess the interrelationships between the operational efficiency improvement and resource recovery practices when deployed simultaneously.

From a practitioners' point of view, the economic models developed in Figure 3, Figure 4 \& Figure 5 provide additional insights on how the operational and resource efficiency dimensions can be addressed in order to meet the food demands of the growing population. This efficiency can be realised through a potential reduction in the current rate of virgin material consumed as well as an increase in the lifetime use of resources through the adoption of resource recovery practices. In addition, the results of the LCA study clearly highlights the environmental impacts corresponding to each resource consumed at every stage of the mango FSC. This impact assessment not only helps the FSC practitioners, including farmers, to adopt and reduce the environmental impact but also assists in creating economic and social value. Furthermore, extrapolating operational efficiency improvement practices and resource recovery practices from a variety of literature to address the Indian mango FSC's inefficiencies will help decision makers improve the overall efficiency of Indian mango FSC. Indeed, implementation of these practices across different industry sectors requires government' intervention. This could include the introduction of effective regulations, laws, policies, and tax which may be in the form of incentives to sustainable processes and application of taxes on the consumption of non-renewable resources.

\section{Limitations}

The limitations of this study are mainly in methodological aspects. Due to unavailability of some of the life cycle inventory data from the region under consideration, global average is used. Hence, using all inventory data corresponding to the geographical location considered might affect the result. Also, the data collection for this study is only from Tamil Nadu, India. In order to generalise the findings of this study more globally, it would be necessary to collect more data. Furthermore, the variation in time period of data collection would impact the result obtained as there is a chance for difference in resource consumed by different machineries and processes used in different time period. The interpretations made in this study are based on the impact categories considered in this 
study. In addition, the specific focus on cultivation, processing, packaging and transportation stages of an FSC provides on limiting factor in this study. As such this study could benefit from including consumption (at the point of sale) and the waste recovery phase.

In summary, this study opens avenues for further research to ensure more sustainable practices in the agricultural sector.

\section{Acknowledgements}

We thank the farmers and managers in the fruit processing industries for their support in the data collection process. 


\section{References}

Accorsi, R., Cascini, A., Cholette, S., Manzini, R., Mora, C., 2014. Economic and environmental assessment of reusable plastic containers: A food catering supply chain case study. Int. J. Prod. Econ. 152, 88-101. https://doi.org/10.1016/j.ijpe.2013.12.014

Accorsi, R., Versari, L., Manzini, R., 2015. Glass vs. plastic: Life cycle assessment of extravirgin olive oil bottles across global supply chains. Sustain. 7, 2818-2840. https://doi.org/10.3390/su7032818

Adekunle I.O, 2013. Precision agriculture: Applicability and opportunities for nigerian agriculture. Middle East J. Sci. Res. 13, 1230-1237. https://doi.org/10.5829/idosi.mejsr.2013.13.9.1004

Agustina, D., Lee, C.K.M., Piplani, R., 2014. Vehicle scheduling and routing at a cross docking center for food supply chains. Int. J. Prod. Econ. 152, 29-41. https://doi.org/10.1016/j.ijpe.2014.01.002

Ahumada, O., Villalobos, J.R., 2011. Operational model for planning the harvest and distribution of perishable agricultural products. Int. J. Prod. Econ. 133, 677-687. https://doi.org/10.1016/j.ijpe.2011.05.015

Ajila, C.M., Aalami, M., Leelavathi, K., Rao, U.J.S.P., 2010. Mango peel powder: A potential source of antioxidant and dietary fiber in macaroni preparations. Innov. Food Sci. Emerg. Technol. 11, 219-224. https://doi.org/10.1016/j.ifset.2009.10.004

Ajila, C.M., Bhat, S.G., Prasada Rao, U.J.S., 2007. Valuable components of raw and ripe peels from two Indian mango varieties. Food Chem. 102, 1006-1011. https://doi.org/10.1016/j.foodchem.2006.06.036

Akbari Kaasgari, M., Imani, D.M., Mahmoodjanloo, M., 2017. Optimizing a vendor managed inventory (VMI) supply chain for perishable products by considering discount: Two calibrated meta-heuristic algorithms. Comput. Ind. Eng. 103, 227-241. https://doi.org/10.1016/j.cie.2016.11.013

Akgul, O., Shah, N., Papageorgiou, L.G., 2012. An optimisation framework for a hybrid first/second generation bioethanol supply chain. Comput. Chem. Eng. 42, 101-114. https://doi.org/10.1016/j.compchemeng.2012.01.012

Al Shamsi, K.B., Compagnoni, A., Timpanaro, G., Cosentino, S., Guarnaccia, P., 2018. A Sustainable Organic Production Model for "Food Sovereignty" in the United Arab Emirates and Sicily-Italy. Sustainability 10, 620. https://doi.org/10.3390/su10030620

Allaoui, H., Guo, Y., Choudhary, A., Bloemhof, J., 2018. Sustainable agro-food supply chain design using two-stage hybrid multi-objective decision-making approach. Comput. Oper. Res. 89, 369-384. https://doi.org/10.1016/j.cor.2016.10.012

Amorim, P., Meyr, H., Almeder, C., Almada-Lobo, B., 2013. Managing perishability in production-distribution planning: A discussion and review. Flex. Serv. Manuf. J. 25, 389413. https://doi.org/10.1007/s10696-011-9122-3

Anbazhagan, V., 2016. Biofertilizer production from fruits and vegetable wastes | Gandhian 
Young Technological Innovation Award.

APEDA, 2018. Exports From India of Mango Pulp [WWW Document]. APEDA. URL http://agriexchange.apeda.gov.in/product_profile/exp_f_india.aspx? categorycode $=0303$ (accessed 2.5.19).

Aramyan, L.H., Ondersteijn, C.J.M., Kooten, O. Van, Oude Lansink, a G.J.M., 2006. Performance indicators in agri-food production chains. Quantifying agri-food supply Chain 47-64. https://doi.org/10.1007/1-4020-4693-6_5

Arora, A., Banerjee, J., Vijayaraghavan, R., MacFarlane, D., Patti, A.F., 2018. Process design and techno-economic analysis of an integrated mango processing waste biorefinery. Ind. Crops Prod. 116, 24-34. https://doi.org/10.1016/j.indcrop.2018.02.061

Audsley, E., Alber, S., 1997. Harmonisation of environmental life cycle assessment for agriculture. CE DG VI-Centre de documentation, Luxembourg.

Azadnia, A.H., Saman, M.Z.M., Wong, K.Y., 2015. Sustainable supplier selection and order lotsizing: An integrated multi-objective decision-making process. Int. J. Prod. Res. 53, 383408. https://doi.org/10.1080/00207543.2014.935827

Babazadeh, R., Razmi, J., Pishvaee, M.S., Rabbani, M., 2017. A sustainable second-generation biodiesel supply chain network design problem under risk. Omega 66, 258-277. https://doi.org/10.1016/J.OMEGA.2015.12.010

Bagh, S., 2005. Some Critical issues on Groundwater in India June 2005 Centre for Water Policy. Water Policy.

Balaji, M., Arshinder, K., 2016. Modeling the causes of food waste in perishable Indian food supply chain. Resour. Conserv. Recycl. 114, 153-167.

Banaeian, N., Mobli, H., Fahimnia, B., Nielsen, I.E., Omid, M., 2018. Green supplier selection using fuzzy group decision making methods: A case study from the agri-food industry. Comput. Oper. Res. 89, 337-347. https://doi.org/10.1016/j.cor.2016.02.015

Banasik, A., Kanellopoulos, A., Claassen, G.D.H., Bloemhof-Ruwaard, J.M., van der Vorst, J.G.A.J., 2017a. Closing loops in agricultural supply chains using multi-objective optimization: A case study of an industrial mushroom supply chain. Int. J. Prod. Econ. 183, 409-420. https://doi.org/10.1016/j.ijpe.2016.08.012

Banasik, A., Kanellopoulos, A., Claassen, G.D.H., Bloemhof-Ruwaard, J.M., van der Vorst, J.G.A.J., 2017b. Assessing alternative production options for eco-efficient food supply chains using multi-objective optimization. Ann. Oper. Res. 250, 341-362. https://doi.org/10.1007/s10479-016-2199-z

Beitzen-Heineke, E.F., Balta-Ozkan, N., Reefke, H., 2017. The prospects of zero-packaging grocery stores to improve the social and environmental impacts of the food supply chain. J. Clean. Prod. 140, 1528-1541. https://doi.org/10.1016/j.jclepro.2016.09.227

Beske, P., Land, A., Seuring, S., 2014. Sustainable supply chain management practices and dynamic capabilities in the food industry: A critical analysis of the literature 152, 131-143. https://doi.org/10.1016/j.ijpe.2013.12.026 
Bharucha, J., 2018. Tackling the challenges of reducing and managing food waste in Mumbai restaurants. Br. Food J. 120, 639-649. https://doi.org/10.1108/BFJ-06-2017-0324

Bligny, J.-C., Pennington, D., Camillis, C. De, Pályi, B., Bauer, C., Schenker, U., King, H., Martin, N., Ponsioen, T., Unger, N., Lundquist, L., Draucker, L., Blomsma, C., Sueys, R., Papagrigoraki, A., Vessia, Ø., Protocol, D., Testing, F.P., 2012. Sustainable Consumption \& Production Round Table ENVIFOOD Protocol Environmental Assessment of Food and Drink Protocol 1-50.

Bongiovanni, R., Lowenberg-Deboer, J., 2004. Precision agriculture and sustainability. Precis. Agric. 5, 359-387. https://doi.org/10.1023/B:PRAG.0000040806.39604.aa

Borghi, A. Del, Gallo, M., Strazza, C., Borghi, M. Del, 2014. An evaluation of environmental sustainability in the food industry through Life Cycle Assessment : the case study of tomato products supply chain 78 .

Brancoli, P., Rousta, K., Bolton, K., 2017. Life cycle assessment of supermarket food waste. Resour. Conserv. Recycl. 118, 39-46. https://doi.org/10.1016/j.resconrec.2016.11.024

Brown, L.R., 2012. Full Planet, Empty Plates: The New Geopolitics of Food Scarcity. Earth Policy Institute, Washington, DC.

Cellura, M., Longo, S., Mistretta, M., 2011. Sensitivity analysis to quantify uncertainty in Life Cycle Assessment: The case study of an Italian tile. Renew. Sustain. Energy Rev. 15, 46974705. https://doi.org/10.1016/J.RSER.2011.07.082

Cerutti, A.K., Bruun, S., Beccaro, G.L., Bounous, G., 2011. A review of studies applying environmental impact assessment methods on fruit production systems. J. Environ. Manage. 92, 2277-2286. https://doi.org/10.1016/j.jenvman.2011.04.018

Chen, X.-P., Cui, Z.-L., Vitousek, P.M., Cassman, K.G., Matson, P.A., Bai, J.-S., Meng, Q.-F., Hou, P., Yue, S.-C., Romheld, V., Zhang, F.-S., 2011. Integrated soil-crop system management for food security. Proc. Natl. Acad. Sci. 108, 6399-6404. https://doi.org/10.1073/pnas.1101419108

Cholette, S., Venkat, K., 2009. The energy and carbon intensity of wine distribution: A study of logistical options for delivering wine to consumers. J. Clean. Prod. 17, 1401-1413. https://doi.org/10.1016/J.JCLEPRO.2009.05.011

Dhawan, V., 2017. Water and Agriculture in India. Backgr. Pap. South Asia Expert panel Dur. Glob. Forum Food Agric. 28.

Diabat, A., Govindan, K., Panicker, V. V, 2012. Supply chain risk management and its mitigation in a food industry. Int. J. Prod. Res. 50, 3039-3050. https://doi.org/10.1080/00207543.2011.588619

Ding, H., Liu, Q., Zheng, L., 2016. Assessing the economic performance of an environmental sustainable supply chain in reducing environmental externalities. Eur. J. Oper. Res. 255, 463-480. https://doi.org/10.1016/j.ejor.2016.05.003

Dos Santos, B.L., Smith, L.S., 2008. RFID in the supply chain. Commun. ACM 51, 127. https://doi.org/10.1145/1400181.1400209 
Dulmin, R., Mininno, V., 2003. Supplier selection using a multi-criteria decision aid method. J. Purch. Supply Manag. 9, 177-187. https://doi.org/10.1016/S1478-4092(03)00032-3

Egilmez, G., Kucukvar, M., Tatari, O., Bhutta, M.K.S., 2014. Supply chain sustainability assessment of the U.S. food manufacturing sectors: A life cycle-based frontier approach. Resour. Conserv. Recycl. 82, 8-20. https://doi.org/10.1016/j.resconrec.2013.10.008

Eskandarpour, M., Dejax, P., Miemczyk, J., Pï ¿²ton, O., 2015. Sustainable supply chain network design: An optimization-oriented review. Omega (United Kingdom) 54, 11-32. https://doi.org/10.1016/j.omega.2015.01.006

Etemadnia, H., Goetz, S.J., Canning, P., Tavallali, M.S., 2015. Optimal wholesale facilities location within the fruit and vegetables supply chain with bimodal transportation options: An LP-MIP heuristic approach. Eur. J. Oper. Res. 244, 648-661. https://doi.org/10.1016/j.ejor.2015.01.044

FAO, 2014. Country Rank in the World by Commodity [WWW Document]. FAO. URL http://www.fao.org/faostat/en/\#home (accessed 10.9.18).

FAO, 2011a. Global food losses and food waste - Extent, causes and prevention. SAVE FOOD An Initiat. Food Loss Waste Reduct. 37. https://doi.org/10.1098/rstb.2010.0126

FAO, 2011b. Food wastage footprint \& Climate Change. Rome.

Frischknecht, R., Editors, N.J., Althaus, H.-J., Doka, G., Dones, R., Heck, T., Hellweg, S., Hischier, R., Nemecek, T., Rebitzer, G., Spielmann, M., 2007. Ecoinvent 2 Overview and Methodology, Ecoinvent Report No1.

Galotto, M., Ulloa, P., 2010. Packaging's Role in Minimizing Food Loss and Waste Across the Supply Chain. Packag. Technol. Sci. 23, 253-266. https://doi.org/10.1002/pts

Garofalo, P., Andrea, L.D., Tomaiuolo, M., Venezia, A., Castrignan, A., 2017. Environmental sustainability of agri-food supply chains in Italy: The case of the whole-peeled tomato production under life cycle assessment methodology 200, 1-12. https://doi.org/10.1016/j.jfoodeng.2016.12.007

Garza-Reyes, J.A., Kumar, V., Chaikittisilp, S., Tan, K.H., 2018. The effect of lean methods and tools on the environmental performance of manufacturing organisations. Int. J. Prod. Econ. 200, 170-180. https://doi.org/10.1016/J.IJPE.2018.03.030

Ghisellini, P., Cialani, C., Ulgiati, S., 2016. A review on circular economy: The expected transition to a balanced interplay of environmental and economic systems. J. Clean. Prod. 114, 11-32. https://doi.org/10.1016/j.jclepro.2015.09.007

Göbel, C., Langen, N., Blumenthal, A., Teitscheid, P., Ritter, G., Göbel, C., Langen, N., Blumenthal, A., Teitscheid, P., Ritter, G., 2015. Cutting Food Waste through Cooperation along the Food Supply Chain. Sustainability 7, 1429-1445. https://doi.org/10.3390/su7021429

Gokarn, S., Kuthambalayan, T.S., 2017. Analysis of challenges inhibiting the reduction of waste in food supply chain. J. Clean. Prod. 168, 595-604. https://doi.org/10.1016/j.jclepro.2017.09.028 
Govindan, K., 2018. Sustainable consumption and production in the food supply chain: A conceptual framework. Int. J. Prod. Econ. 195, 419-431. https://doi.org/10.1016/j.ijpe.2017.03.003

Govindan, K., Kadziński, M., Sivakumar, R., 2017. Application of a novel PROMETHEE-based method for construction of a group compromise ranking to prioritization of green suppliers in food supply chain. Omega (United Kingdom) 71, 129-145. https://doi.org/10.1016/j.omega.2016.10.004

Grimm, J.H., Hofstetter, J.S., Sarkis, J., 2016. Exploring sub-suppliers' compliance with corporate sustainability standards. J. Clean. Prod. 112, 1971-1984. https://doi.org/10.1016/j.jclepro.2014.11.036

Grimm, J.H., Hofstetter, J.S., Sarkis, J., 2014. Critical factors for sub-supplier management: A sustainable food supply chains perspective. Int. J. Prod. Econ. 152, 159-173. https://doi.org/10.1016/j.ijpe.2013.12.011

Guinée, J.B., 2002. Handbook on life cycle assessment : operational guide to the ISO standards. Kluwer Academic Publishers.

Hobson, K., 2016. Closing the loop or squaring the circle? Locating generative spaces for the circular economy. Prog. Hum. Geogr. 40, 88-104. https://doi.org/10.1177/0309132514566342

Hoekstra, A.Y., Mekonnen, M.M., Chapagain, A.K., Mathews, R.E., Richter, B.D., 2012. Global Monthly Water Scarcity: Blue Water Footprints versus Blue Water Availability. PLoS One 7, 32688. https://doi.org/10.1371/journal.pone.0032688

Iakovou, E., Bochtis, D., Vlachos, D., Aidonis, D., 2015. Sustainable agrifood supply chain management. Supply Chain Manag. Sustain. Food Networks. https://doi.org/10.1002/9781118937495.ch1

Irani, Z., Sharif, A.M., 2016. Sustainable food security futures: Perspectives on food waste and information across the food supply chain. J. Enterp. Inf. Manag. 29, 171-178. https://doi.org/10.1108/JEIM-12-2015-0117

ISO, 2006. ISO 14040:2006 - Environmental management -- Life cycle assessment -- Principles and framework.

Jeffries, N., 2017. A story of regeneration and reforestation from Eritrea. Carbon Manag. https://doi.org/10.4155/cmt.12.20

Ju, M., Osako, M., Harashina, S., 2017. Food loss rate in food supply chain using material flow analysis. Waste Manag. 61, 443-454. https://doi.org/10.1016/j.wasman.2017.01.021

Kalmykova, Y., Sadagopan, M., Rosado, L., 2018. Circular economy - From review of theories and practices to development of implementation tools. Resour. Conserv. Recycl. 135, 190201. https://doi.org/10.1016/J.RESCONREC.2017.10.034

Kamalahmadi, M., Mellat-Parast, M., 2015. Developing a resilient supply chain through supplier flexibility and reliability assessment. Int. J. Prod. Res. 54, 302-321. https://doi.org/10.1080/00207543.2015.1088971org/10.1080/00207543.2015.1088971 
Kumar, A., Jain, V., Kumar, S., 2014. A comprehensive environment friendly approach for supplier selection. Omega 42, 109-123. https://doi.org/10.1016/J.OMEGA.2013.04.003

Kyriakopoulou, K., Papadaki, S., Krokida, M., 2015. Life cycle analysis of $\beta$-carotene extraction techniques. J. Food Eng. 167, 51-58. https://doi.org/10.1016/j.jfoodeng.2015.03.008

Labuschagne, C., Brent, A.C., Van Erck, R.P.G., 2005. Assessing the sustainability performances of industries. J. Clean. Prod. 13, 373-385. https://doi.org/10.1016/j.jclepro.2003.10.007

Lehtinen, U., 2012. Sustainability and local food procurement: A case study of Finnish public catering. Br. Food J. 114, 1053-1071. https://doi.org/10.1108/00070701211252048

Lemaire, G., Franzluebbers, A., Carvalho, P.C. de F., Dedieu, B., 2014. Integrated crop-livestock systems: Strategies to achieve synergy between agricultural production and environmental quality. Agric. Ecosyst. Environ. 190, 4-8. https://doi.org/10.1016/j.agee.2013.08.009

Li, D., Wang, X., Chan, H.K., Manzini, R., 2014. Sustainable food supply chain management. Int. J. Prod. Econ. 152, 1-8. https://doi.org/10.1016/j.ijpe.2014.04.003

Li, X., Baki, F., Tian, P., Chaouch, B.A., 2014. A robust block-chain based tabu search algorithm for the dynamic lot sizing problem with product returns and remanufacturing. Omega 42, 75-87. https://doi.org/10.1016/J.OMEGA.2013.03.003

Liu, Z., Wang, Y., Geng, Y., Li, R., Dong, H., Xue, B., Yang, T., Wang, S., 2019. Toward sustainable crop production in China: An emergy-based evaluation. J. Clean. Prod. 206, 1126. https://doi.org/10.1016/j.jclepro.2018.09.183

Longo, S., Mistretta, M., Guarino, F., Cellura, M., 2017. Life Cycle Assessment of organic and conventional apple supply chains in the North of Italy 140, 654-663. https://doi.org/10.1016/j.jclepro.2016.02.049

MacArthur, E., 2013a. The Circular Economy: A New Development Strategy in China. Ellen MacArthur Found. 10, 4-8. https://doi.org/10.1162/108819806775545321

MacArthur, E., 2013b. Towards the Circular Economy, Ellen MacArthur Foundation. Cowes, UK. https://doi.org/10.1162/108819806775545321

Manfredi, M., Vignali, G., 2014. Life cycle assessment of a packaged tomato puree: A comparison of environmental impacts produced by different life cycle phases. J. Clean. Prod. 73, 275-284. https://doi.org/10.1016/j.jclepro.2013.10.010

Ministry of Agriculture, 2013. Post-Harvest Profile of Mango 2013 Government of India Ministry of Agriculture (Department of Agriculture \& Cooperation).

Mirabella, N., Castellani, V., Sala, S., 2014. Current options for the valorization of food manufacturing waste: A review. J. Clean. Prod. 65, 28-41. https://doi.org/10.1016/j.jclepro.2013.10.051

Mogale, D.G., Dolgui, A., Kandhway, R., Kumar, S.K., Tiwari, M.K., 2017. A multi-period inventory transportation model for tactical planning of food grain supply chain. Comput. Ind. Eng. 110, 379-394. https://doi.org/10.1016/j.cie.2017.06.008 
Mogale, D.G., Kumar, S.K., Kumar Tiwari, M., 2016. Two Stage Indian Food Grain Supply Chain Network Transportation-Allocation Model. IFAC-PapersOnLine 49, 1767-1772. https://doi.org/10.1016/j.ifacol.2016.07.838

Mota, B., Gomes, M.I., Carvalho, A., Barbosa-Póvoa, A., 2015. Supply chain design and planning accounting for the Triple Bottom Line. Comput. Aided Chem. Eng. 37, 18411846. https://doi.org/10.1016/B978-0-444-63576-1.50001-7

Nemecek, T.Q., Bengoa, X., Rossi, V.Q., Sebastien Humbert, Q., Lansche, J.A., Mouron, P.A., 2014. World Food LCA Database Methodological Guidelines for the Life Cycle Inventory of Agricultural Products.

Ngoc, U.N., Schnitzer, H., 2009. Sustainable solutions for solid waste management in Southeast Asian countries. Waste Manag. 29, 1982-1995. https://doi.org/10.1016/j.wasman.2008.08.031

Notarnicola, B., Sala, S., Anton, A., McLaren, S.J., Saouter, E., Sonesson, U., 2017. The role of life cycle assessment in supporting sustainable agri-food systems: A review of the challenges. J. Clean. Prod. 140, 399-409. https://doi.org/10.1016/j.jclepro.2016.06.071

Noya, I., Aldea, X., González-García, S., M. Gasol, C., Moreira, M.T., Amores, M.J., Marín, D., Boschmonart-Rives, J., 2017. Environmental assessment of the entire pork value chain in Catalonia - A strategy to work towards Circular Economy. Sci. Total Environ. 589, 122129. https://doi.org/10.1016/j.scitotenv.2017.02.186

Noya, L.I., Vasilaki, V., Stojceska, V., González-García, S., Kleynhans, C., Tassou, S., Moreira, M.T., Katsou, E., 2018a. An environmental evaluation of food supply chain using life cycle assessment: A case study on gluten free biscuit products. J. Clean. Prod. 170, 451-461. https://doi.org/10.1016/j.jclepro.2017.08.226

Noya, L.I., Vasilaki, V., Stojceska, V., González-García, S., Kleynhans, C., Tassou, S., Moreira, M.T., Katsou, E., 2018b. An environmental evaluation of food supply chain using life cycle assessment: A case study on gluten free biscuit products. J. Clean. Prod. 170, 451-461. https://doi.org/10.1016/j.jclepro.2017.08.226

Paksoy, T., Bektaş, T., Özceylan, E., 2011. Operational and environmental performance measures in a multi-product closed-loop supply chain. Transp. Res. Part E Logist. Transp. Rev. 47, 532-546. https://doi.org/10.1016/j.tre.2010.12.001

Papapostolou, C., Kondili, E., Kaldellis, J.K., 2011. Development and implementation of an optimisation model for biofuels supply chain. Energy 36, 6019-6026. https://doi.org/10.1016/j.energy.2011.08.013

Parajuli, R., Dalgaard, T., Birkved, M., 2018. Can farmers mitigate environmental impacts through combined production of food, fuel and feed? A consequential life cycle assessment of integrated mixed crop-livestock system with a green biorefinery. Sci. Total Environ. 619-620, 127-143. https://doi.org/10.1016/j.scitotenv.2017.11.082

Park, Y.S., Egilmez, G., Kucukvar, M., 2016. Emergy and end-point impact assessment of agricultural and food production in the United States: A supply chain-linked Ecologicallybased Life Cycle Assessment. Ecol. Indic. 62, 117-137. 
https://doi.org/10.1016/j.ecolind.2015.11.045

Parwez, S., 2014. Supply chain dynamics of Indian agriculture: Reference to information technology and knowledge management. Stewart Postharvest Rev. 10.

https://doi.org/10.2212/spr.2014.1.3

Piercy, N., Rich, N., 2015. The relationship between lean operations and sustainable operations. Int. J. Oper. Prod. Manag. 35, 282-315. https://doi.org/10.1108/JOPM-03-2014-0143

Pishvaee, M.S., Razmi, J., 2012. Environmental supply chain network design using multiobjective fuzzy mathematical programming. Appl. Math. Model. 36, 3433-3446. https://doi.org/10.1016/j.apm.2011.10.007

Prosman, E.J., Sacchi, R., 2016. New environmental supplier selection criteria for circular supply chains: Lessons from a consequential LCA study on waste recovery. J. Clean. Prod. 172, 2782-2792. https://doi.org/10.1016/j.jclepro.2017.11.134

Rentizelas, A., Shpakova, A., Mašek, O., 2018. Designing an optimised supply network for sustainable conversion of waste agricultural plastics into higher value products. J. Clean. Prod. 189, 683-700. https://doi.org/10.1016/j.jclepro.2018.04.104

Rother, M., Shook, J., 2003. Learning to see : value stream mapping to create value and eliminate muda. Lean Enterprise Institute.

Roy, P., Nei, D., Orikasa, T., Xu, Q., Okadome, H., Nakamura, N., Shiina, T., 2009. A review of life cycle assessment (LCA) on some food products. J. Food Eng. 90, 1-10. https://doi.org/10.1016/J.JFOODENG.2008.06.016

Ruviaro, C.F., Gianezini, M., Brandão, F.S., Winck, C.A., Dewes, H., 2012. Life cycle assessment in Brazilian agriculture facing worldwide trends. J. Clean. Prod. 28, 9-24. https://doi.org/10.1016/j.jclepro.2011.10.015

Seuring, S., Müller, M., 2008. From a literature review to a conceptual framework for sustainable supply chain management. J. Clean. Prod. 16, 1699-1710. https://doi.org/10.1016/j.jclepro.2008.04.020

Sharifzadeh, M., Garcia, M.C., Shah, N., 2015. Supply chain network design and operation: Systematic decision-making for centralized, distributed, and mobile biofuel production using mixed integer linear programming (MILP) under uncertainty. Biomass and Bioenergy 81, 401-414. https://doi.org/10.1016/j.biombioe.2015.07.026

Sharpe, S., Agarwal, R., 2014. Strengthening Industrial Ecology's Links with Business Studies: Insights and Potential Contributions from the Innovation and Business Models Literature. Resources 3, 362-382. https://doi.org/10.3390/resources3020362

Siddh, M.M., Soni, G., Jain, R., Sharma, M.K., Yadav, V., 2017. Agri-fresh food supply chain quality (AFSCQ): a literature review. Ind. Manag. Data Syst. 117, 2015-2044. https://doi.org/10.1108/IMDS-10-2016-0427

SimaPro, 1988. SimaPro, the world's leading LCA software [WWW Document]. URL https://simapro.com/ (accessed 8.23.18). 
So, S., Sun, H., 2015. Lean thinking as organisational practice in enabling supply chain sustainability. Int. J. Environ. Technol. Manag. 18, 291. https://doi.org/10.1504/IJETM.2015.072140

Soto-Silva, W.E., Nadal-Roig, E., González-Araya, M.C., Pla-Aragones, L.M., 2016. Operational research models applied to the fresh fruit supply chain. Eur. J. Oper. Res. 251, 345-355. https://doi.org/10.1016/j.ejor.2015.08.046

Soysal, M., Bloemhof-Ruwaard, J.M., Haijema, R., Van Der Vorst, J.G.A.J., 2015. Modeling an Inventory Routing Problem for perishable products with environmental considerations and demand uncertainty. Int. J. Prod. Econ. 164, 118-133. https://doi.org/10.1016/j.ijpe.2015.03.008

Strazza, C., Magrassi, F., Gallo, M., Del Borghi, A., 2015. Life Cycle Assessment from food to food: A case study of circular economy from cruise ships to aquaculture. Sustain. Prod. Consum. 2, 40-51. https://doi.org/10.1016/j.spc.2015.06.004

Su, B., Heshmati, A., Geng, Y., Yu, X., 2013. A review of the circular economy in China: Moving from rhetoric to implementation. J. Clean. Prod. 42, 215-227. https://doi.org/10.1016/j.jclepro.2012.11.020

TNAU, 2017. Horticulture :: Fruits:: Mango [WWW Document]. URL http://agritech.tnau.ac.in/horticulture/horti_fruits_mango.html (accessed 8.23.18).

Tsai, W.-H., Hung, S.-J., 2009. A fuzzy goal programming approach for green supply chain optimisation under activity-based costing and performance evaluation with a value-chain structure. Int. J. Prod. Res. 47, 4991-5017. https://doi.org/10.1080/00207540801932498

Tukker, A., Jansen, B., 2006. Environmental Impacts of Products: A Detailed Review of Studies. J. Ind. Ecol. 10, 159-182. https://doi.org/10.1162/jiec.2006.10.3.159

Validi, S., Bhattacharya, A., Byrne, P.J., 2014. A case analysis of a sustainable food supply chain distribution system - A multi-objective approach. Int. J. Prod. Econ. 152, 71-87. https://doi.org/10.1016/j.ijpe.2014.02.003

Vergine, P., Salerno, C., Libutti, A., Beneduce, L., Gatta, G., Berardi, G., Pollice, A., 2017. Closing the water cycle in the agro-industrial sector by reusing treated wastewater for irrigation. J. Clean. Prod. 164, 587-596. https://doi.org/10.1016/j.jclepro.2017.06.239

Willersinn, C., Mack, G., Mouron, P., Keiser, A., Siegrist, M., 2015. Quantity and quality of food losses along the Swiss potato supply chain: Stepwise investigation and the influence of quality standards on losses. Waste Manag. 46, 120-132. https://doi.org/10.1016/j.wasman.2015.08.033

Winkler, H., 2011. Closed-loop production systems-A sustainable supply chain approach. CIRP J. Manuf. Sci. Technol. 4, 243-246. https://doi.org/10.1016/j.cirpj.2011.05.001

Wolf, M.A., Chomkhamsri, K., Brandao, M., Pant, R., Ardente, F., Pennington, D.W., Goralczyk, M., 2010. ILCD Handbook-General Guide for Life Cycle Assessment Detailed Guidance. https://doi.org/10.2788/38479

Yin, G., Liu, L., Yuan, C., 2015. Assessing environmental risks for high intensity agriculture 
using the material flow analysis method - a case study of the Dongting Lake basin in South Central China. Environ. Monit. Assess. 187, 472-499. https://doi.org/10.1007/s10661-0154696-y

Yusuf, Y.Y., Gunasekaran, A., Musa, A., El-Berishy, N.M., Abubakar, T., Ambursa, H.M., 2013. The UK oil and gas supply chains: An empirical analysis of adoption of sustainable measures and performance outcomes. Int. J. Prod. Econ. 146, 501-514. https://doi.org/10.1016/J.IJPE.2012.09.021

Zeng, H., Chen, X., Xiao, X., Zhou, Z., 2017. Institutional pressures, sustainable supply chain management, and circular economy capability: Empirical evidence from Chinese ecoindustrial park firms. J. Clean. Prod. 155, 54-65. https://doi.org/10.1016/j.jclepro.2016.10.093

Zhang, Y., Jiang, Y., 2017. Robust optimization on sustainable biodiesel supply chain produced from waste cooking oil under price uncertainty. Waste Manag. 60, 329-339. https://doi.org/10.1016/j.wasman.2016.11.004 